\title{
Are Student-Athletes in the NCAA Exploited?
}

by

Kevin Churchill

A thesis submitted to the Faculty of Graduate and Postdoctoral Affairs in partial fulfillment of the requirements for the degree of

Master of Arts

in

Philosophy

Carleton University

Ottawa, Ontario

(C) 2015, Kevin Churchill 


\begin{abstract}
In this thesis I will be examining the claim that American student-athletes are exploited, and I will begin by motivating the issue as one worthy of philosophical inquiry. After then looking at the legitimacy of the moral claim that the governing body of American college athletics uses to deny payment to student-athletes, I will look at different theories of exploitation and how they might apply to college athletics. Then, using Alan Wertheimer's theory of exploitation, I will argue that student-athletes are exploited in a morally significant way by their schools. Finally, I will outline an initial proposal for a new system of college athletics that avoids the exploitation of student-athletes. I will argue that despite some practical and theoretical issues, we can design a system that avoids the exploitation of studentathletes.
\end{abstract}




\section{Acknowledgements}

Thanks to the all the professors in the department of philosophy with whom I studied during my time at Carleton; this thesis is a culmination of the all the work I did under their supervision. Special thanks to my thesis supervisor Vida Panitch; without her help, guidance, and willingness to listen and respond to my innumerable problems and arguments, the completion of this thesis simply would not have been possible. 


\section{Table of Contents}

Abstract ........................................................................................................................ii

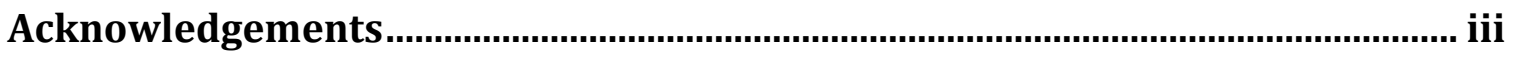

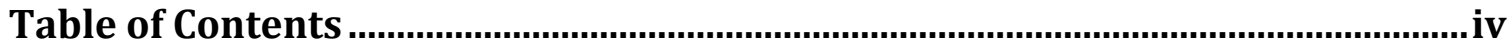

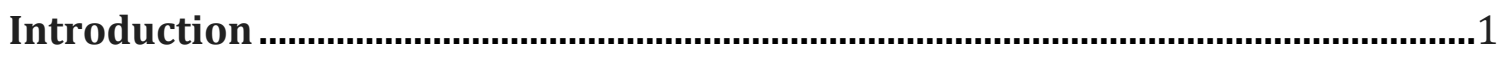

Chapter One Motivating the Issue: the NCAA and Exploitation ...................................6

Chapter Two The Principle of Amateurism: Non-Commodification and Sport........ 18

Chapter Three Examining Theories of Exploitation.......................................................42

Chapter Four A Critique of Wertheimer's View on College Sports..............................67

Chapter Five Practical and Theoretical Issues with the Introduction of Pay-for-Play

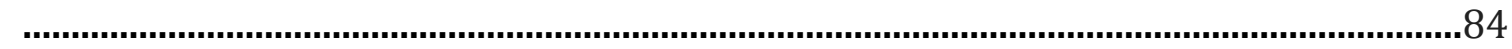

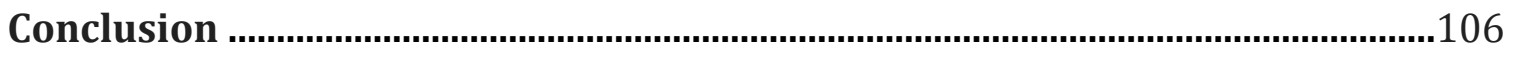

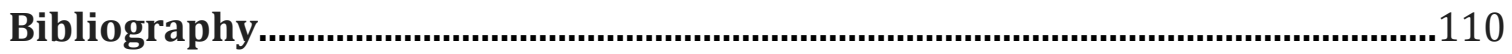




\section{Introduction}

In his original 2001 entry on exploitation in the Stanford Encyclopedia of Philosophy, Alan Wertheimer listed five scenarios of alleged exploitation. The first of these scenarios was about college athletics in the United States. It read as follows: 'The president of Stanford University claimed that big-time college athletics "reeks of exploitation," because the universities gain a great deal of revenue from the services of the athletes while the athletes (whose graduation rate is much lower than that of non-athletes) gain little from their college experience.'1 In substantive revisions of the entry in both $2005^{2}$ and $2008,{ }^{3}$ this scenario remained the first example of alleged exploitation. In the most recent revision, which was 2012, this example was removed from the article.

Although Wertheimer devoted a chapter of his 1996 book Exploitation to the topic of exploitation in American college sports, his argument there is unsatisfying. That he subsequently removed discussion of the issue from his SEP entry entirely, and that other ethicists and political philosophers have devoted scant attention to the issue seems not only odd, but also neglectful, given the increasing moral relevance of the worry. Recently, the claim that student-athletes are exploited by the schools for which they play has been getting more and more attention in the media, in social sciences, and in the legal system. Jay Bilas, a former basketball player at

\footnotetext{
${ }^{1}$ Alan Wertheimer. "Exploitation." The Stanford Encyclopedia of Philosophy. http://plato.stanford.edu/archives/win2001/entries/exploitation/ ${ }^{2}$ Alan Wertheimer. "Exploitation”. The Stanford Encyclopedia of Philosophy. http://plato.stanford.edu/archives/sum2005/entries/exploitation/ ${ }^{3}$ Alan Wertheimer. Exploitation. The Stanford Encyclopedia of Philosophy. http://plato.stanford.edu/archives/fall2008/entries/exploitation/
} 
Duke University and current analyst for ESPN who has notably attacked colleges for exploiting student-athletes has the following to say on the topic:

An athlete is not exploited when he is fairly compensated in a business transaction outside of the institution. To the contrary, one could more persuasively argue that an athlete is exploited when he is expressly disallowed from realizing his value while his reputation and skill are being used to realize a profit for others. ${ }^{4}$

Bilas is far from the only member of the national media to begin to claim that student-athletes are exploited. From popular economist and blogger Andy Schwarz, to beat writers around the country, many claim that student-athletes are exploited. Since the common-sense notion has gained much backing and publicity, one might think that those who study and write about exploitation would take note and explore the issue. This has not been done. Much has changed since Alan Wertheimer penned his single chapter on exploitation and college sports in 1996, but nothing notable has been written on the topic since.

The final goal of this project is to lend clarity and credibility to the claim that student-athletes in the NCAA are exploited. By splitting the task into five chapters, I will examine and explore the issues that contribute to whether or not we can say with confidence that student-athletes are exploited. The first chapter will be used to set the stage of college athletics in the United States. In that chapter I will introduce the National Collegiate Athletic Association (NCAA) and examine how and why the NCAA is set up the way it is. It is in this chapter that I will introduce the enormously important Principle of Amateurism, and the moral non-commodification claim that it is based upon. I will also introduce the relevant legal cases that lend credibility to

${ }^{4}$ National College Players Association. "Introduction and Background." http://www.ncpanow.org/research/body/Introduction_and_Background.pdf 
the topic as one worthy of philosophical analysis.

The second chapter will be an investigation of commodification literature and how it might effect the issue at hand. In this chapter I will closely examine the moral claim upon which the Principle of Amateurism is based. The moral claim is a non-commodification claim; this claim states that the goods associated with sport (teamwork, competition, etc.) are in some way spoiled by the involvement of money in sport. I will examine arguments made by Michael Walzer and Elizabeth Anderson, and finally arguments made by co-authors Adrian Walsh and Richard Giulianotti in their book Ethics, Money, and Sport - The Sporting Mammon. They advance the claim that the hypercommodification (intense commodification) of sport can corrupt the goods brought about by being involved in sport as either a player or a fan. I will examine each of the arguments they make in support of their claim and eventually argue that all of them - except for one - are unconvincing, and that there is nothing wrong with money being involved in sport.

In Chapter Three I will begin to take a closer look at broader literature on exploitation; it is in this chapter that I will examine what exactly it means to be exploited. After all, for us to know whether or not student-athletes are exploited, we have to know what it means for somebody to be exploited. I will begin by examining Marxist conceptions of exploitation. By drawing on work from contemporary systemic theorists, and theorists who continue in the Marxist tradition, I will eventually argue that this framework is not the right one to use in defining the particular moral harm of exploitation. After this, I will turn to the Kantian account of Allen Wood, who argues that exploitation has to do with failing to properly respect 
others, and then to the transactional account of Robert Goodin, who argues that every case of exploitation has to do with the violation of a particular moral duty. After discussing why these approaches do not quite work, I will eventually exposit Alan Wertheimer's theory of exploitation, and argue that his theory is the correct one to use. Wertheimer's theory does the best job of capturing our intuitions about the moral wrong of exploitation, while also having the tools to say that some cases of exploitation are worse than others.

In Chapter Four I will examine Wertheimer's 1996 chapter on exploitation in college sports. After discussing his view on the topic, I will argue that he makes two vital mistakes in applying his own theory to the case of college athletics in the United States. First, I will argue that he misidentifies the scope of the exploitation, and so more student-athletes are exploited than he believes. Second, I will argue that he does not recognize that NCAA schools in fact act fraudulently and coercively in their transactions with student-athletes. Because of the importance of fraud and coercion in determining the moral force of exploitation in his theory, this second mistake is particularly important. It means that rather than being a relatively unimportant case of exploitation according to his theory, it is in fact a case of exploitation with a strong enough moral force to warrant interference.

The fifth and final chapter of this project will have two parts. In the first section I will identify practical issues that could arise with the introduction of payfor-play in college athletics, and then I will propose a drastic reworking of the NCAA that addresses these issues and avoids the exploitation of student-athletes. I will 
then identify and respond to a significant theoretical critique - namely that my system creates unfair inequalities - of the system I propose.

By the end of this project, I will have achieved five major goals: first, I will have shown that the topic of exploitation and college sports is one worthy of philosophical inquiry; second, I will have shown that alleged issues with the commodification of sport are in fact non-existent; third, I will have shown that Wertheimer's theory of exploitation best matches our considered intuitions about what exploitation means and that we should use this theory to examine the possible exploitation in college athletics; fourth, I will have shown that student-athletes are in fact exploited, and this exploitation is morally significant to the point of the transaction warranting interference; and fifth, I will have shown that despite some practical and theoretical issues, a re-working of college athletics to implement payfor-play is not only feasible but could in fact help solve some current issues that the NCAA is facing. 


\section{Chapter One \\ Motivating the Issue: the NCAA and Exploitation}

College athletics in the United States is, by a recent account, an eleven billion dollar a year business, ${ }^{5}$ and the student-athletes whose labour and time are the basis of this business are not allowed to be paid. Recently, this apparent injustice has been gaining more and more attention in the United States: from sports journalists to big-time sports lawyers to the athletes themselves, people are starting to recognize that there might something wrong with the current system. Many have described the particular moral wrong as that of exploitation. In recently published articles in the New York Post ${ }^{6}$, in The Nation ${ }^{7}$, and by a prominent sports journalist ${ }^{8}$ (to name only a few), critics of the current model of college sports have repeatedly claimed that student-athletes are exploited. Perhaps more damning, three current class action lawsuits against the National Collegiate Athletic Association (NCAA), which is the governing body of college sports in the United States, use the term exploitation to describe the moral wrong committed by the NCAA. Despite all of this,

\footnotetext{
5 Josh Peter and Steve Berkowitz, "Special Report: Coaches hit jackpot in NCAA system." USA Today, April 2nd, 2014.

http://www.usatoday.com/story/sports/ncaab/2014/04/02/ncaa-tournamentbasketball-coaches-compensation-obannon-case/7208877/.

${ }^{6}$ Linda Chavez, "How Colleges Exploit Athletes." New York Post, March 28 ${ }^{\text {th }}, 2014$. http://nypost.com/2014/03/28/how-colleges-exploit-athletes/.

7 Dave Zirin, "The NCAA: Posterboy for Corruption and Exploitation." The Nation, April 1st, 2013. http://www.thenation.com/article/173307/ncaa-poster-boycorruption-and-exploitation\#.

${ }^{8}$ Jay Bilas, who has a public history of tweeting and writing about college athletes being exploited. See: Trey Williams. "Bilas: NCAA shouldn't limit compensation." Johnson City Press, October 2 $2^{\text {nd }}, 2013$. http://www.johnsoncitypress.com/article/111460/bilas-ncaa-shouldnt-limitcompensation.
} 
and despite the fact that college athletics has been identified as a potential case of exploitation, ${ }^{9}$ philosophers have committed very little time and very few pages to exploring the issue of exploitation and American college athletics. The aim of my thesis is to explore the issues that surround the current structure of college athletics in the United States, and provide clarity to the claim that student-athletes in the NCAA are exploited.

In this first chapter, I will discuss the facts of the case and why they are relevant to the discussion of exploitation. This will involve two major steps: first, it will involve examining the landscape and set-up of the NCAA as it currently is. To understand the issue, we must understand how the current system is set up. Second, it will involve examining four current legal issues that the NCAA faces. The first three are class-action lawsuits against the NCAA, and the fourth is a recent unionization movement by members of the Northwestern University football team. The aim of this introductory chapter is to motivate the issue as one both worthy of and in need of philosophical inquiry. With that in mind, let us begin.

The NCAA is an organization that governs more than 1,200 colleges and universities that compete in intercollegiate sport in the United States. The schools are split up into three divisions - Division 1, Division 2, and Division 3 - based loosely on the amount of money that schools put into their athletic programs. The goal of this is to make sure that each school is competing against schools with a

\footnotetext{
${ }^{9}$ Most notably by Alan Wertheimer. See Alan Wertheimer. Exploitation (Princeton: Princeton University Press, 1996).
} 
similar attitude and commitment to college sport. ${ }^{10}$ So, teams that compete in Division 1 generally have the biggest athletic budgets and the best teams. As well, each division is split up into conferences. There are 32 conferences in Division 1 men's basketball, for instance, and teams play most of their regular season games against other teams in their conference. Each division (1,2, and 3) is self-governed, but its rules and regulations must fit within the NCAA's overarching principles. Chief among the NCAA's principles is the Principle of Amateurism, which states the following:

Student-athletes shall be amateurs in an intercollegiate sport, and their participation should be motivated primarily by education and by the physical, mental and social benefits to be derived. Student participation in intercollegiate athletics is an avocation, and student-athletes should be protected from exploitation by professional and commercial enterprises. ${ }^{11}$

This principle is the cornerstone to the current college athletics system, and there are two goals of the Principle of Amateurism: The first is to ensure that student-athletes do not receive financial benefits other than what is formally known as "grant-in-aid" (commonly referred to as an athletic scholarship). ${ }^{12}$ Grant-in-aid can be provided by universities but cannot exceed the price of tuition and necessary living expenses (i.e., room and board). ${ }^{13}$ The goal of keeping money out of studentathletes' hands is to make sure that athletes remain involved in athletics for the goods intrinsic to athletic competition; or, as the NCAA puts it, for the physical,

${ }^{10}$ NCAA. "Membership." http://www.ncaa.org/about/who-we-are/membership.

${ }^{11}$ NCAA Manual 2013-2014, Section 2.9.

12 NCAA Manual 2013-2014, Section 12.01.4.

${ }^{13}$ NCAA Manual 2013-2014, Section 15.02.5. 
mental, and social benefits to be derived. ${ }^{14}$ Here, the NCAA is making a noncommodification claim, which is to say that the goods associated with participation in sport are spoiled by the involvement of money. ${ }^{15}$ So, to make sure that these goods are not spoiled, student-athletes should remain amateurs and not be paid. The only thing that should be paid for is their education. This brings us to the second goal of the principle of amateurism, which is to "recognize and support the primacy of the academic mission of its member institutions."16 In other words, it is supposed to ensure that student-athletes are students first, and that their involvement in interuniversity sport remains secondary to the pursuit of their academic goals.

On the face of it, these might seem like reasonable goals. While I would disagree with them, there are those who would argue that money actually does spoil the social goods (teamwork, competition, fraternity, to name a few) associated with sport. And, to make sure that student-athletes remain primarily focused on their academics seems like a valuable goal. Let us imagine that this position is correct, for the time being. ${ }^{17}$ In Chapter 2 I will take on this view in full, but for now we need not do so. If this is indeed why the NCAA wants to stop athletes from being paid, one would think that the same principle would apply to all those involved in the sport, and indeed to all facets of the sport. This would mean that college sports in the United States should not be commercialized. But, this is far from the case. The

${ }_{14}^{14}$ NCAA Manual 2013-2014, Section 2.9.

15 This claim is substantial, and there is literature that would back it up. A more thorough discussion will follow in Chapter Two.

${ }^{16}$ NCAA Manual 2013-2014, Section 14.01.4.

${ }^{17}$ Chapter Two will be spent showing that this position is not in fact the correct position. 
University of Texas, which has the largest athletics-related revenue of any college in the US, made 163 million dollars last year from its athletics programs. ${ }^{18}$ The average salary for the head coach of a men's basketball team that made the 68-team final tournament is just under two million dollars a year, with the highest paid coach bringing in just fewer than ten million dollars. ${ }^{19}$ In Division 1 college football, the average coaching salary is 1.64 million dollars and the highest paid coach makes just under six million dollars. ${ }^{20}$ The average athletic director of a Division 1 school makes around $\$ 500,000$, with the highest paid athletic director making 3.2 million dollars. ${ }^{21}$ This all happens in a system whose governing body regulates using a rule that is based on a claim that that money spoils sports.

One of the current lawsuits against the NCAA focuses on the Principle of Amateurism. The lawsuit, which is a class-action lawsuit, seeks to end what it claims is an unlawful price-fixing by the NCAA and its five major conferences. ${ }^{22}$ Under the Sherman Act, which is the major American anti-trust law, price-fixing is illegal unless it has pro-competitive benefits. The lawsuit claims that under the Sherman

${ }^{18}$ Steve Berkowitzet al. "NCAA Finances." USA Today. http://www.usatoday.com/sports/college/schools/finances/. ${ }^{19}$ Josh Peter and Steve Berkowitz. "Special Report: Coaches hit jackpot in NCAA system." USA Today, April 2nd, 2014. http://www.usatoday.com/story/sports/ncaab/2014/04/02/ncaa-tournamentbasketball-coaches-compensation-obannon-case/7208877/.

${ }^{20}$ Erik Brady, Jodi Upton, and Steve Berkowitz. "College football coaches continue to see salary explosion." USA Today, November $20^{\text {th }}, 2012$. http://www.usatoday.com/story/sports/ncaaf/2012/11/19/college-footballcoaches-contracts-analysis-pay-increase/1715435/.

${ }^{21}$ Erik Brady, Jodi Upton, and Steve Berkowitz. "Major college Ads averaging over \$500,000 in pay." USA Today, March 6, 2013. http://www.usatoday.com/story/sports/college/2013/03/06/college-athleticsdirectors-salaries-increase/1964239/.

22 Jenkins et al vs. NCAA (2014), 4:2014cv02758, United States District Court, District of New Jersey. http://a.espncdn.com/pdf/2014/0317/NCAA_lawsuit.pdf. 
Act the fact that the NCAA fixes the price of student-athletes' labour is illegal. It claims that the NCAA and its member organizations have entered into "what amounts to cartel agreements with the avowed purpose and effect of placing a ceiling on the compensation that may be paid to these athletes for their services."23 Because of these agreements, student-athletes are "exploited by the [NCAA] and its member institutions under false claims of amateurism."24 The lawsuit is seeking an injunction to end the NCAA's ability to place a ceiling on compensation that could be provided for the service of student-athletes.

The lawsuit goes on to say that the NCAA has steered far from its principle of amateurism and onto a path of commercialization, "signing billion-dollar contracts wholly disconnected from the interests of student-athletes." 25 Further, schools have abandoned regional, geographically defined conferences and in an effort to secure more money from better media deals often play in conferences with schools nowhere near their campus. As the lawsuit points out, student-athletes at West Virginia University must travel at least 800 miles for each of its away games during a season. ${ }^{26}$ While this is an extreme example, it is far from an isolated example. These types of arrangements are based solely on the generation of money, and completely "disregard the welfare of athletes who have to travel thousands of miles in the service of creating income for their schools." ${ }^{27}$ It seems quite clear that the NCAA has abandoned an amateur model of sport, and that it has increasingly

\footnotetext{
23 Jenkins et al vs. NCAA, 2.

24 Jenkins et al vs. NCAA, 2.

25 Jenkins et al vs. NCAA, 2.

26 Jenkins et al vs. NCAA, 30.

27 Jenkins et al vs. NCAA, 30.
} 
commercialized college athletics. Only the players themselves have been left out of this commercialization process.

The second lawsuit against the NCAA, "O'Bannon vs. NCAA," has recently been decided, and the NCAA is in the process of appealing the ruling. The lawsuit aims to strike down current NCAA rules by appealing to the Sherman Act. The lawsuit takes aim at the NCAA, Electronic Arts, Incorporated (a videogame company, hereafter EA), and the College Licensing Company (the NCAA's licensing body, hereafter the CLC). In many of its video games, EA used the names, numbers, and visual likeness of former student-athletes. This process was approved, and indeed sold to EA, by the CLC and therefore by the NCAA. The lawsuit claimed that the defendants had unlawfully fixed the compensation that former student-athletes can receive for the use of their image, likeness, and names. ${ }^{28}$ It claimed that the NCAA has "illegally restrained trade in order to commercially exploit former studentathletes previously subject to its control, with such exploitation affecting those individuals well into their post-collegiate competition lives."29

The lawsuit went on to claim that by denying former student-athletes compensation for the use of their image and likeness, the NCAA is denying these former student-athletes rights that all other members of society enjoy. "Former student-athletes do not share in these revenues even though they have never given informed consent to the widespread and continued commercial exploitation of their

28 O’Bannon v. NCAA (2009), 4:2009cv03329. United States District Court, District of Northern California. http://www.pbs.org/wgbh/pages/frontline/money-andmarch-madness/etc/licensing-litigation.html, 4.

${ }^{29}$ O’Bannon v. NCAA, 4. 
images." ${ }^{30}$ These images and likeness have been used by the NCAA (and by companies to which the NCAA has licensed the use of such images) in the rebroadcast of classic games, in DVDs of games, in highlight film sales and rentals, in on-demand streaming and sales of games and clips, in sales to corporate advertisers, in photo sales, in video game sales, and in jersey sales. The court ruled that the NCAA did in fact violate anti-trust law by putting these restrictions in place, and ordered that the NCAA must begin to pay student-athletes for the use of their likeness. ${ }^{31}$

It seems clear that the NCAA is not committed to keeping money out of sport. Instead, the NCAA is only committed to keeping money out of the hands of studentathletes. Certainly it seems that the claim cannot be that money spoils the goods associated with sport, because money is everywhere in college sport, and the NCAA actively seeks out ways to make more money. Remember, though, that the second stated goal of the principle of amateurism is to make sure that student-athletes remain students first. Perhaps an exploration of this will give us a better understanding of why student-athletes should not be paid.

Unfortunately for the NCAA, there are two legal proceedings that show that the NCAA's commitment to ensuring the academic success of its student-athletes is almost non-existent. In a recent class-action lawsuit naming the University of North Carolina and the NCAA as defendants, the plaintiffs claim that over the course of 22

\footnotetext{
30 O'Bannon v. NCAA, 7.

${ }^{31}$ Finding of Fact and Conclusions of Law. Case 4:09-cv-03329-CW, District Court of the Northern District of California.

https://s3.amazonaws.com/s3.documentcloud.org/documents/1272774/obannoncourt-decision.pdf.
} 
years, and under the regulation of the NCAA, "UNC steered hundreds of college athletes into sham 'paper classes' that they were not required to attend."32 These classes "required little to no work, were not taught by a faculty member, and involved no interaction with a faculty member."33 The lawsuit then goes on to name 30 different instances of academic fraud occurring in the NCAA over the last few decades, and claims that despite knowledge of all of these cases the NCAA has not changed its policies or created any policy in order to stop academic fraud. All of this, the lawsuit claims, despite the fact that the NCAA claims to value academics:

The NCAA and its member schools insist that their mission and purpose is to educate and to prevent the exploitation of college athletes. Yet it is the schools, the conferences, and the NCAA that are engaging in exploitation, subverting the educational mission in the service of the big business of college athletics. ${ }^{34}$

The lawsuit is based on the findings of an independent investigation made into academics at UNC. The remainder of the lawsuit, which is 100 pages long, is a scathing display of facts that show the NCAA is in no way committed to ensuring the success of the academic mission of its member schools. ${ }^{35}$

A recent ruling by the National Labour Relations Board (NLRB) seems to further break down the notion that student-athletes are students first. In December of 2013, the Northwestern University football team (a Division 1 team) brought a case to the NLRB with the purpose of gaining the right to unionize and bargain for

\footnotetext{
32 McCants et el v. NCAA and the University of North Carolina at Chapel Hill (2015), 1:2015cv00176, Superior Court of North Carolina, County of Durham. http://www.cbssports.com/images/blogs/Hausfeld-complaint.pdf, 2.

${ }^{33}$ McCants et el v. NCAA, 2.

34 McCants et el v. NCAA, 3-4.

35 To discuss the specifics of the lawsuit in its entirety would take too long. Suffice to say it is damning evidence.
} 
their services. After hearing testimony from both sides, the NLRB ruled that studentathletes at Northwestern were, by the letter of the law, employees that had the right to unionize. Part of this decision was based on the fact that members of the Northwestern football team could not possibly to said to be primarily students. The following is from the NLRB ruling:

The players spend 50 to 60 hours per week on their football duties during a one-month training camp prior to the start of the academic year and an additional 40 to 50 hours per week on those duties during the three or four month football season. Not only is this more hours than many undisputed full-time employees work at their jobs, it is also many more hours than the players spend on their studies. In fact, the players do not attend academic classes while in training camp or the first few weeks of the regular season. After the academic year begins, the players still continue to devote 40 to 50 hours per week on football-related activities while only spending about 20 hours per week attending classes... it cannot be said that they are 'primarily students' who 'spend only a limited number of hours performing their athletic duties.' ${ }^{36}$

The single quotations in the above paragraph are claims made by Northwestern University in testimony against players' right to unionize. Despite Northwestern's claims, student-athletes at the Division 1 level have been found to be primarily athletes. This is not to say that they are not also students, but it is to say that they are certainly not primarily students. Other testimony by Northwestern players showed that players were not allowed to take certain classes because they would interfere with the team's practice schedule. ${ }^{37}$ This conclusion - that studentathletes spend more time on their sport than on their school - is supported by a study done by the NCAA in 2006, which shows that student-athletes spent an

${ }^{36}$ NLRB Region 13 Case 13-RC-121359. "Decision and Direction of Election." March 26th, 2014. http://www.nlrb.gov/case/13-RC-121359, 18.

37 NLRB Region 13 Case 13-RC-121359, "Decision and Direction of Election." 11. 
average of 46 hours a week on their sport. ${ }^{38}$ This is another example of academics taking a secondary role behind athletics in Division 1 college sports in the United States.

On its own, there is nothing wrong with a student-athlete being primarily an athlete. And, I will argue in Chapter Two that there is nothing wrong with money being involved in college sport. These are only issues because the NCAA claims to be committed to the opposite of both of these ideas, and in fact uses its commitment to these ideas as a rationale to not allow players to be paid. This seems very wrong (in Chapter Four I will argue it is fraudulent), and clearly there seems to be legal precedent to wonder if the NCAA is in fact acting illegally. If the above lawsuits are successful, it would not be the first time that the NCAA was found guilty of breaking anti-trust law. Even before the recently decided O'Bannon lawsuit, the NCAA had a history of breaking anti-trust law. In 1984, the NCAA was found to be in violation of the Sherman Act by attempting to limit the number of live football games that could be televised locally. ${ }^{39}$ In 1998, the NCAA was again found to be in violation of the Sherman Act by attempting to set a price cap on what part time coaches could be paid. ${ }^{40}$ Most recently - in 2001 - the NCAA was sued by five of its member institutions under United States anti-trust law. While the case did not go to court, the legal action resulted in the NCAA settling, and paying a significant amount to the suing schools. ${ }^{41}$ All of this is meant to show that the NCAA has a history of trouble with the law, specifically with violating anti-trust law.

${ }^{38}$ McCants et el v. NCAA, 25.

39 Jenkins et al vs. NCAA, 30 .

40 Jenkins et al vs. NCAA, 30.

${ }^{41}$ Jenkins et al vs. NCAA, 30. 
But, the purpose of this thesis is not to legally condemn the NCAA: others seem to be doing that quite well without my help. My aim is to explore and clarify the claim that schools exploit their student-athletes. Just because the NCAA has previously been involved in illegal activity and is currently facing legal issues does not mean that it exploits its member institutions student-athletes. Nor does the fact that these lawsuits - as well as sports journalists and other mass media - claim that the schools exploit their student-athletes actually make it so. By exploring the lawsuits and the NLRB ruling, my aim was twofold: first, to show that there is good reason to explore this issue; and second, to provide the readers with the necessary background information about the NCAA and its practices so that the forthcoming philosophical discussion of the concept of exploitation can be thought about in a context that is relevant to this thesis. The specifics that have just been discussed will come up throughout the rest of this thesis, in particular in Chapter Four when we begin to discuss Alan Wertheimer's take on exploitation in college athletics.

At this point, it should be clear that this topic is worthy of philosophical inquiry. We generally think of exploitation as a serious moral harm, and so the repeated claim that thousands of student-athletes are exploited is a claim worth exploring. The beginning of this exploration will begin in the next chapter, where I will examine the moral claim that is at the basis of the NCAA's Principle of Amateurism. 


\section{Chapter Two \\ Non-Commodification and Sport}

A major part of the first chapter of this project was spent discussing the NCAA's Principle of Amateurism, which is based upon a moral claim about the effect that money can have on sport. The claim made by the NCAA is that the involvement of money in college sport would ruin the "mental, physical, and social benefits to be derived from participation in intercollegiate sport." 42 In order to avoid this happening, the NCAA requires that student-athletes remain amateurs and not be paid for participation in sport anything more than the value of their athletic scholarship. The NCAA does not provide argumentation for its non-commodification claim; instead, they simply assert it as true. In this chapter I will examine some of the philosophical literature at the basis of this claim. This will involve introducing commodification literature in a broad sense, before exploring how it applies to sport.

My overall goal for this thesis is to figure out if student-athletes in the NCAA are exploited, and examining the argument about the non-commodification of sport is an important step. If the NCAA's claim about the negative effects of the commodification of sport is right, then they would have good reason to not pay student-athletes. This would have a huge effect on whether or not we think studentathletes are exploited. Or, at the very least, it will be relevant to determining the moral force of the exploitation, something that I will discuss in more depth in Chapter Four. This chapter will be split into four sections: the first section will be

42 NCAA Manual 2013-2014, Section 2.9. 
spent introducing commodification literature by briefly looking at arguments made by Michael Sandel, Elizabeth Anderson, and Michael Walzer. Sections two and three will be spent examining the first two arguments - that the commodification of sport can illegitimately change our motives and that commodification of sport can lead us to treat athletes as mere means - that are made by Adrian Walsh and Richard Giulianotti in their book Ethics, Money, and Sport - This sporting Mammon. Section four will be spent examining the last two arguments made by Walsh and Giulianotti, which are that the commodification of sport can lead to issues of distributive injustice and that the commodification of sport will lead to the long term downfall of sport.

In these last three sections, I will return to the views of Walzer and Anderson. While Walsh and Giulianotti are the authors that take on the commodification of sport in the most depth, the commodification arguments made by Walzer and Anderson can help explain what exactly Walsh and Giulianotti are objecting to. Let us begin our investigation of the non-commodification argument made by the NCAA by looking at Sandel. In the end, I will argue that only one of the four critiques that Walsh and Giulianotti level at the commodification of sport is worrisome, and that the NCAA cannot legitimately restrict payment to studentathletes on the basis of this claim.

\section{I}

In the first chapter of his book What Money Can't Buy: the Moral Limits of Markets, Michael Sandel says that over the last several decades we have unwittingly 
put a price on everything. We have begun to use the open market to allocate things that were never allocated by the market before, and the result is the expansion of markets and market values into sphere of life in which they simply do not belong. ${ }^{43}$ As he puts it, "we drifted from having a market economy to being a market society." ${ }^{44}$ We now use the market - in some form or another - to allocate health, education, public safety, national security, criminal justice, recreation, and even procreation. 45

Sandel's major contribution to commodification literature is his articulation of two distinct moral worries raised by commodification. These are inequality and corrosion. The inequality worry is that as market norms determine the distribution of an increasing number of goods, inequality of wealth begins to have a greater effect than it should. The corrosion worry is that when we distribute certain goods through the market, the way we value those goods is somehow undermined; as Sandel puts it, "market values crowd out non-market values worth caring about."46

When it comes to equality, Sandel convincingly argues that money would not matter so much if all that someone could do with more money was buy yachts, sports cars, and fancy vacations. ${ }^{47}$ However, when having more money allows you to buy better health care, better education, more political influence, and homes in safer

\footnotetext{
43 Michael Sandel. What Money Can't Buy: The Moral Limits of Markets. (New York: Farrar, Straus, and Giroux Books, 2012), 7.

44 Sandel, What Money Can't Buy, 10.

45 Sandel, What Money Can't Buy, 8.

46 Sandel, What Money Can't Buy, 9.

47 Sandel, What Money Can't Buy, 9.
} 
neighborhoods, inequality of wealth becomes a much larger issue. ${ }^{48}$ Let us briefly turn to Michael Walzer for a more thorough look at the equality issue.

In the first chapter of his book Spheres of Justice, Walzer introduces his theory of goods. There are two important claims to understand. The first is that the value of a good is determined by its social meaning. ${ }^{49}$ Goods do not have meanings that are distinct from the agents valuing them. A good example of this is a cross: with nobody around, it means nothing; when put in front of a parish at a church, it is loaded with value..$^{50}$ The second claim is that goods should be distributed according to the principle that reflects the way they are valued. Different goods are valued in different ways and for different reasons, so to distribute them all the same way would undermine the meaning of the goods. Instead, goods should be understood as belonging to spheres, and spheres have independently defined distributive principles. ${ }^{51}$

Walzer argues that in any given era, there is a dominant good. A dominant good is a good that allows the holders of it to thereby control other social goods. ${ }^{52}$ It changes the distributive principle of a sphere to one that does not reflect the way a good is valued. At different points in history, Walzer argues that physical strength, familial reputation, religious standing, political office, or wealth have all been dominant goods; he also argues those that controlled them used their dominance to

\footnotetext{
48 Sandel, What Money Can't Buy, 8.

${ }^{49}$ Michael Walzer, Spheres of Justice. (New York: Basic Books, 1983), 7.

50 Walzer, Spheres of Justice, 7.

51 Walzer, Spheres of Justice, 8-9.

52 Walzer, Spheres of Justice, 10.
} 
gain control over a wide range of social goods. ${ }^{53}$ In a capitalist society, money is dominant. ${ }^{54}$ Walzer argues that any dominance is unjust: whenever a social good is used to gain influence or control in a sphere in which it does not belong, this is inherently wrong. ${ }^{55}$ The dominance of money and the distribution of all goods in accordance with market norms have allowed money to gain unjust influence across spheres. The wealthy can gain an advantage over the poor in just about any sphere of life. This inequality, according to Walzer, is unjust.

The second moral harm that Sandel identifies in the first chapter of What Money Can't Buy is that of corrosion. Some things should not be distributed by markets or according to market norms because distributing them in this way somehow corrupts their value. When we decide that something should be governed by the norms of the market, we are agreeing that it is appropriate to treat those things as instruments of personal profit and gain. But, not all goods are appropriately valued in this way. Let us turn to Anderson, the philosopher who best helps ground the worry.

Anderson argues that different norms govern different types of goods, and that wrongful commodification occurs when the norms of the market govern the production, distribution, and enjoyment of goods that do not belong in the sphere of the market. Anderson identifies five social norms that are unique to market transactions and the open market. The first norm is that market relations are

53 Walzer, Spheres of Justice, 10.

${ }^{54}$ Walzer, Spheres of Justice, 11.

55 Walzer, Spheres of Justice, 10. 
impersonal. ${ }^{56}$ She argues that producers and consumers of economic goods are typically strangers, and that individuals view their relations with others as purely helping themselves achieve some independently defined end. The second norm is that an individual, in market relations, is free to pursue his own personal advantage unrestrained by any consideration for the advantage of others. ${ }^{57}$ In fact, Anderson claims that the market relies on the fact that each agent will take care of himself and his own interests. The third norm is that goods traded on the market are exclusive and rivals in consumption..$^{58}$ They are exclusive in that if I am able to enjoy the good, it means that you are not; they are exclusive in that if I purchase a good, it reduces the amount that can be purchased by others. The fourth norm is that the market is purely want regarding: matters of value are simply matters of personal taste. ${ }^{59}$ There is no judgment of the validity or worthiness of a desire. Ability to pay is all that matters. Lastly, dissatisfaction with a market relation is expressed primarily by exit, not by voice..$^{60}$ If you are unhappy with the terms of a relationship or the demands of a producer, you simply do not exercise your purchasing power on that good.

With these five norms in mind, Anderson argues we have a pretty precise account of a market good. A good is economic if its production, distribution, and enjoyment are properly governed by these five norms. ${ }^{61} \mathrm{~A}$ good is not economic if

\footnotetext{
${ }^{56}$ Elizabeth Anderson, "Ethical Limitations of the Market." Economics and Philosophy 6 (1990): 182.

57 Anderson, "Ethical Limitations of the Market," 183.

58 Anderson, "Ethical Limitations of the Market," 183.

${ }^{59}$ Anderson, "Ethical Limitations of the Market," 183.

${ }^{60}$ Anderson, "Ethical Limitations of the Market," 183.

61 Anderson, "Ethical Limitations of the Market," 183.
} 
this is not the case. The worry about the corrosive tendency of the market can be understood on Anderson's view as a worry about the impersonal norms of use that govern the market realm being applied to a sphere where goods should be valued in a different way. The values and norms of the market "crowd out" the typical values and norms of certain spheres. When we apply norms like impersonality and selfinterest to goods that have different types of value (be it shared, personal, or sentimental), goods come to be valued only for their instrumental use. If I am selling a family heirloom at a garage sale and you and I argue over its dollar value, we are degrading the true value of the item; to me it has a sentimental value that cannot be realized in monetary terms. The things and people that we love have a type of value that cannot be expressed in market terms, and so to apply market norms to them undermines their true value.

Now that I have introduced commodification literature in a broad sense, and we understand the two major issues that are typically identified as problematic with commodification, let us turn to the topic of the commodification of the sporting world.

\section{II}

In the remainder of this chapter I will address each of the four possible moral pathologies - defined as any undesirable feature of the incorporation of a good or activity into the realm of commodities ${ }^{62}$ - that Walsh and Giulianotti identify and I

${ }^{62}$ Adrian Walsh and Richard Giulianotti, Ethics, Money and Sport - This sporting mammon (New York: Routldege Publishing, 2007), 30. 
will ask a series of questions about each. First, is the possible moral pathology a legitimate worry? If it is, then is the worry actually turning into a reality? And, if the moral pathology turns out to be both worrisome and coming into reality, then what should be done? I will also relate each moral pathology back to the two issues identified by Sandel as problematic with commodification. In the end I will advance the view that the commodification of sport is only an issue for one of the reasons that Walsh and Giulianotti identify.

Walsh and Giulianotti acknowledge two assumptions that they make before entering into their discussion of how the commodification of sport could lead to moral pathologies. The first assumption they make is that certain "ideals and values embodied in the ethos of a community of sports practitioners are valuable." 63 This seems rather uncontroversial; many people claim that sport is valuable in some way. The second assumption the authors make, which I believe is a far more controversial claim, is that the interests and preferences of traditional fans are normatively significant. While the most relevant commodification critiques that will be discussed in this chapter do not rely on this claim, it is worth discussing. Let us begin by examining the first moral pathology that Walsh and Giulianotti identify. Walsh and Giulianotti identify the possibility that the commodification of sport could lead to the transformation of the structure of our motives by the market. ${ }^{64}$ Essentially, they are claiming that there are certain reasons people should play sports, and to make financial gains is not one of them. Sport should be pursued

${ }^{63}$ Adrian Walsh and Richard Giulanotti. "This Sporting Mammon: A Normative Critique of the Commodification of Sport." Journal of the Philosophy of Sport 28 (2001): 54.

${ }^{64}$ Walsh and Giulianotti, Ethics, Money and Sport, 32. 
for its own sake, and not for the sake of money. ${ }^{65}$ When agents pursue sport for its own sake, this is when the morally valuable goods associated with sport are realized. The authors identify what some of these goods are: competing at one's best against other similarly skilled athletes; the development of skills; exhibiting sportsmanship and fair play; and community and national representation. ${ }^{66}$ This is not meant to be an exhaustive list of the possible goods intrinsic to sport. We could easily add in teamwork, excellence, hard work, and dedication, among others.

Walsh and Giulianotti claim that these motivations are intrinsically valuable: that is, they are ends in themselves, rather than a means to some other end. They explicitly say that they do not mean to say that these goods are intrinsically valuable in the sense of objective value that can be independent of valuers. ${ }^{67}$ They just mean that these are goods pursued for their own sake. ${ }^{68}$ When an athlete pursues sport motivated by one of these goods, they are pursuing sport for its intrinsically valuable aspects. This, of course, is not the case when an athlete pursues sport for financial reasons. It is important to note, though, that the claim is not that financial compensation should not be among the motivations for an athlete to pursue a sport, but instead that it should not be the sole or predominant aim of an athlete. ${ }^{69} \mathrm{Walsh}$ and Giulianotti believe that it is possible to enjoy the goods intrinsic to sport if money is a secondary motivation. As long as the intrinsic goods are the main motivation, Walsh and Giulianotti are fine with money being involved. From here,

\footnotetext{
65 Walsh and Giulianotti, Ethics, Money and Sport, 32.

${ }^{66}$ Walsh and Giulianotti, Ethics, Money and Sport, 35-36.

67 Walsh and Giulianotti, Ethics, Money and Sport, 37.

${ }^{68}$ Walsh and Giulianotti, Ethics, Money and Sport, 37.

${ }^{69}$ Walsh and Giulianotti, Ethics, Money and Sport, 38.
} 
there are two questions to ask: why should we be worried about money being the main motivation? And, if we should be worried about it, is it actually happening?

A good way to understand the worry is that our motivations for playing sport are changing even though the way we generally value sport is not changing. Even though we value sport for the goods intrinsic to it, somehow our motivational structure is illegitimately changed by the influence of money. People still value sport because of teamwork, competition, and so on. But, when there is as much money involved in sport as there is today, it could be possible that we become motivated not by these goods, but purely by money. Then, as our motivation changes from the goods intrinsic to sport to financial motive, we might begin valuing sport only for financial reasons. This does seem like a worrisome issue. Is it true, though, that commodification of sport actually leads to money being the sole motivator?

Walsh and Giulianotti claim that there is a strong tie between commodification and venality (financial motivation being the sole or principle motivation), to the point that in almost all places that money becomes involved, financial motives take over. ${ }^{70}$ This is exactly what Michael Sandel has in mind when he says the market values crowd out other values, and what Elizabeth Anderson has in mind when she says that market norms have the tendency to take over and erode the values of other spheres. Anderson sums up the worry quite well:

For a certain dimension of value to be realized in a good, or for the good to serve as the vehicle for the realization of our ideals, the production, distribution, and enjoyment of this good must take place within the context of certain social relations. To trade the good on the market, or otherwise to subject its conditions of valuation to market forces and market norms, is to

70 Walsh and Giulianotti, Ethics, Money and Sport, 42. 
remove it from these social relations or to undermine their integrity. ${ }^{71}$ What we need to decide is whether involving money in the realm of sport crowds out the goods of sport and the way we value those goods. Are the goods of sport undermined by the involvement of money? In an important way, it seems that the market actually reinforces, rather than undermines, the things that we value most in sport. When an organization pays an athlete for his services, the athlete is being paid because of the way he exemplifies the goods that we associate with sport: the higher the skill level of an athlete, the better the athlete works as a teammate, the more selfless the athlete is, and the more competitive the athlete is, the higher the financial reward. Rather than corroding the goods and values associated with the sphere of sports, a financial motive might actually help reinforce the value of these goods. Something interesting would happen to an athlete if he stopped valuing these sorts of goods and only valued money: he would become a worse player, and his market value would drop drastically.

One might object that a player could have financial gain as his main motivation and because of this motivation become very good at exemplifying the goods we associate with sport. Because he wanted to make money, he could increase his skill level, he could be a good teammate, he could compete extremely hard. He could exemplify all of these goods just in order to make money. There are two issues with this objection: the first is that as a matter of fact, it would be extremely difficult to exemplify all of these goods if one did not find them valuable. The second is to point out that if financial motivation actually can make a person

${ }^{71}$ Anderson, "Ethical Limitations of the Market," 202. 
exemplify all of the things that we think are valuable about sport, then maybe financial motivation is a good thing in this instance.

In the end, I would argue that because of the types of goods that are intrinsic to the realm of sport, the realm of sport actually has built in checks and balances that punish athletes who do not value sport for the goods associated with it. To be a successful athlete, one must exemplify the goods that are associated with sport: the market just reinforces this by giving financial reward to athletes that exemplify these goods and by withholding financial reward from those who do not.

The first possible moral pathology of commodification, then, is not a worry, This is because the market actually works to reinforce, rather than corrode, the values that we associate with sport, and because a successful athlete is one who exemplifies these goods. The market works in the realm of sport to financially reward athletes who best exemplify the goods we associate with sport. This is quite different from undermining or corroding those values, or from illegitimately changing our motives.

\section{III}

The next possible moral pathology that Walsh and Giulianotti identify is that the commodification of sport leads to viewing athletes as mere means, and leads to viewing sport itself as a mere means. ${ }^{72}$ The second part of this worry, about sport being viewed as a mere means, is not particularly interesting. In fact, I would argue that sport is nothing more than a means to an end. It is valuable because people

72 Walsh and Giulianotti, Ethics, Money and Sport, 65. 
value it; its value comes from its usefulness to valuers. Instead of dealing with this objection, I will deal with the interesting claim that commodification leads to viewing athletes as a mere means. This line of critique is distinctly Kantian in origin, and relies on his work in The Groundwork for Metaphysics of Morals. In this work, Kant argues that a thing can have either a price or a dignity, but not both. ${ }^{73}$ Price and dignity are mutually exclusive. In his Humanity Formula of the Categorical Imperative, Kant claims that we should treat persons "never simply as a means but always at the same time as an end."74 He claims that putting a price on a person is denying them dignity, and thereby treating them as a mere means. Walsh and Giulianotti are not the first authors to appeal to Kant in an attempt to describe commodification: remember Elizabeth Anderson's claims that economic goods (goods that should be governed by market norms) have use value. ${ }^{75}$ This means that their value comes from how they can be used, and the fact that they can be used as a mere means. This type of value is contrasted with higher forms of value, such as dignity. ${ }^{76}$ This critique is a second version of the corrosion worry, where the thing being corroded is a person, rather than social goods.

To relate this back to sport, the claim is that whenever an athlete becomes commodified (becomes paid for his work), he is being treated as if he only has a use value, and therefore as a mere means. Walsh and Giulianotti recognize that there are counterpoints to this claim, and so they make a softer claim. They argue that when

\footnotetext{
${ }^{73}$ Kant, Immanuel. Groundwork for the Metaphysics of Morals. http://www.earlymoderntexts.com/pdfs/kant1785.pdf, p. 33.

${ }^{74}$ Kant, Immanuel. Groundwork for the Metaphysics of Morals. http://www.earlymoderntexts.com/pdfs/kant1785.pdf, p. 29.

75 Anderson, "Ethical Limitations of the Market," 181.

76 Anderson, "Ethical Limitations of the Market," 181.
} 
something is commodified, there is a strong tendency to treat it as a mere means. ${ }^{77}$ This does not mean that as a matter of logical fact commodification entails treatment as a mere means. Instead, it is descriptive in stating that there is a strong correlation between commodification and treatment as a mere means. ${ }^{78}$ So, when an athlete is commodified, there is a strong tendency to treat him or her as a mere means. If this were the case, it might indeed be very worrisome. Let us now discuss whether or not it is the case.

There is good reason to doubt Walsh and Giulianotti's claim, but let us first make an important distinction: we must realize that what is being commodified is an athlete's particular skill set, not the athlete himself. The athlete is not being valued in economic terms, but the skill set that he possesses and the traits that he possesses are being valued in economic terms. The worry that the authors seem to be putting forward is that by placing value on a skill set, we often begin to treat the athlete as if this is his only value, and he is thereby treated as a mere means. This is an extremely important distinction to make.

Now, one way to see if this tendency holds is by comparing the norms of the market to the norms that govern the sale of an athlete's skill set. If they are the same, we might have good reason to worry about how the athlete is being viewed, and whether or not he is being viewed as a mere means. If it turns out that the norms of the market do not apply to the sale of an athlete's skill set, this is probably because market norms do not fully control the market in sports and athletes are not viewed solely for their use value.

77 Walsh and Giulianotti, Ethics, Money and Sport, 69.

78 Walsh and Giulianotti, Ethics, Money and Sport, 69. 
With this in mind, let us turn back to Elizabeth Anderson, and let us imagine the process of a player "selling" his skill set on the open market. In certain cases, it will make more sense to imagine the market interaction between a fan and a team, rather than a player and the team. The five norms of a market interaction are impersonality, freedom to pursue individual interest, exclusivity, want-regarding nature of the market, and dissatisfaction via exit.

Immediately, we can see that an athlete's skill set does not meet the typical norms of the market: the norm of impersonality does not apply. In fact, part of what might help a player choose where to sign a contract is the people in the organization, and the other players he will play with. Impersonality simply does not apply. The second norm, that an individual is free to pursue his own interest unrestrained by the interests of others, is applicable. In the end, the athlete decides (with his own best interest in mind) where to play. The third norm, that goods on the market are exclusive and rivals in consumption only partially applies. It is true that an athlete's skill set is rival in consumption: when a player signs with a team, it reduces the number of players that can be signed by other teams. But, in a very important sense, a player's skill set is not exclusive. It is enjoyed by sometimes millions of fans anytime the player plays a game. The enjoyment and appreciation of a skill set is distinctly non-exclusive. The fourth feature is that the market is purely want regarding, and that matters of value are personal. This applies: sport is just one of the things that a person can choose to spend money on. The last norm, that dissatisfaction is expressed through exit not voice, does not fit. If a player is unhappy with his organization, he might choose to express this through voice. Even 
more to the point, fans and media often effectively voice dissatisfaction and actually effect change with organizations by expressing their dissatisfaction through voice.

So, it seems that a player's skill set does not fit the description of a typical economic good. Some of the norms apply, but not all of them. This actually fits quite well with Anderson's overall view. As she points out, goods often overlap spheres, and are valued in multiple ways in multiple spheres. ${ }^{79}$ When this happens, the norms that govern the distribution of the good will also be from different spheres. ${ }^{80}$ This seems like an excellent way of describing what is happening in sport. An athlete's skill set is valued as a commodity (as having use-value) in the sphere of the market, but it is also valued for other reasons in the sphere of sport. When an athlete is appreciated in the sphere of sport, he is appreciated in a way wholly consistent with treating someone as an end. He is appreciated for the way he embodies some of the goods associated with sport: teamwork, excellence, competition, and fair play. As we discussed earlier in the chapter, it just so happens that a player who embodies these goods is also highly valuable in a financial sense, and so a player is also valued as a commodity. Importantly, though, he is not valued as a mere means to end. He is also valued, consistently, as an end in himself. So, this second worry about commodification in sport does not hold. While it would be worrisome if an athlete were valued as a mere means, it turns out that while athletes are valued as means, they are still valued as ends at the same time.

This means that neither of the two critiques of the commodification of sport that I marked as being particularly relevant to college sports are actually good

79 Anderson, "Ethical Limitations of the Market," 183.

80 Anderson, "Ethical Limitations of the Market," 183. 
critiques. The goods of sport are not the sort of goods whose value cannot be realized while an athlete receives remuneration for his athletic services. This means that an athlete can receive financial reward and still value the goods of sport the way we think that they should be valued. Let us now turn to Walsh and Giullianotti's final two critiques of the commodification of sport.

\section{IV}

The third possible moral pathology that Walsh and Giulianotti identify is distributive injustice. ${ }^{81}$ Here, we move away from arguments that focus on the corrosion issue and towards issues that have more to do with the equality issue. Walsh and Giulianotti claim that there are three ways in which the commodification of sport can lead to an unjust distribution of the goods associated with sports. ${ }^{82}$ Essentially, there are three types of goods that get unjustly distributed when commodification happens. The authors claim that some goods associated with sports (they give television access to major sporting events as an example) can be thought of as basic needs goods. ${ }^{83}$ This first group I am not going to spend much time discussing, because I believe it is a group of goods that does not actually exist. While many basic needs theorists actually list participation in sport as a basic need, ${ }^{84}$ to call viewership of sport a basic need is a huge stretch. One would have to grossly distort the meaning of basic needs to have any such goods count as a basic

\footnotetext{
81 Walsh and Giulianotti, Ethics, Money and Sport, 82.

82 Walsh and Giulianotti, Ethics, Money and Sport, 82.

83 Walsh and Giulianotti, Ethics, Money and Sport, 99.

${ }^{84}$ Martha Nussbaum, for instance, lists the enjoyment of recreational activities as a core capability.
} 
needs good. We should not be willing to do this, and so we will dismiss this first group at the outset.

The second group of goods is what Walsh and Giulianotti call universal access goods. They claim that when a group of people (sports fans, particularly poor sports fans) once had access to a good (live sports or free television broadcast of sports) and have that access taken away, there is an unjust distribution occurring. ${ }^{85}$ I think we have good reason to doubt this claim as well, for two reasons. First, even if some people have been excluded, commodification might actually be increasing the number of people who are fans of a sport. Consider the following facts about sports viewership in 2012: there over 60,000 hours of sports programming broadcast in the United States in; over 100 millions viewers watch NFL football on Thanksgiving Day; 12.4 million users access the site NFL.com each month; 45 million viewers tuned in to watch NBA games on Christmas Day; and 6.1 million users access NBA.com each month. ${ }^{86}$ Whatever goods are associated with sports viewership are being accessed by an unprecedented number of people. It seems that the commodification of sports might actually have the effect of making sport accessible to a larger, rather than a smaller, audience. Walsh and Giulianotti, though,

\footnotetext{
85 Walsh and Giulianotti, Ethics, Money and Sport, 94.

${ }^{86}$ Nielsen. "State of the Media: 2012 Nielsen Year in Sports Report." January 18 ${ }^{\text {th }}$, 2013. http://www.nielsen.com/us/en/insights/reports/2013/state-of-the-media-2012-year-in-sports.html
} 
think that this benefit is outweighed by the fact that some fans might be ruled out by an inability to pay. ${ }^{87}$ This brings up an important question.

Why should we think that sports viewership is the type of good that should be provided free of charge? This second version of distributive injustice actually turns out to be the same as the basic needs worry. Most things that are provided regardless of ability to pay are basic needs goods, or goods that are needed to achieve equality. Earlier in the chapter, I briefly described Michael Walzer's description of the inequality issue in commodification. When goods that are vital to life or to equality become distributed by ability to pay, an injustice has occurred. For instance, education is provided by some states regardless of ability to pay because having a basic education is a vital component of having equality of opportunity. Regardless of what you end up choosing to do with your life, having some sort of an education is significant. The same argument has been made about health care: without free health care, those unable to pay for health care would be at a massive disadvantage and their opportunity to pursue their conception of the good life would be threatened. ${ }^{88}$ When people are restricted from access to these types of goods because of an inability to pay, an injustice has occurred. So, often these goods are distributed according to need, rather than ability to pay.

It seems clear that viewership of sport (or whatever goods are associated with sport viewership) is not among these types of goods. It does not seem like the

\footnotetext{
${ }^{87}$ Sandel claims something similar: his take on the phenomenon of increasing ticket prices has been dubbed the "skyboxification" of sports. See: Sandel, What Money Can't Buy, 173-176.

${ }^{88}$ Norman Daniels makes this argument in Equal Opportunity and Health Care, and more recently in Just Health: Meeting Health Needs Fairly.
} 
social meaning of sport makes it such that the distribution of sport to viewers should be governed by need rather than ability to pay. There is not a good enough reason to count sports viewership as among the goods that should be provided free of charge. Furthermore, as stated before, commodification of sport has arguably led to more viewership and appreciation for sport, not less. One would think that Walsh and Giulianotti would support this aspect of the commodification of sport.

The third issue that Walsh and Giulianotti identify as a possible distributive injustice is in the area they call merit goods. ${ }^{89}$ These are goods that should be distributed according to desert or merit. Here, the authors identify a genuinely troubling critique of the commodification of sport. To explain the depth of the critique, another return to Michael Walzer is needed.

We earlier listed the goods we associate with the sphere of sport, and included, among others, competing at one's best against other similarly skilled athletes; the development of skills; exhibiting sportsmanship and fair play; and community and national representation. Based on the way we value sport, the distributive principle within sport should be one of merit: those who best display these traits deserve to win, or to receive special recognition. Championship trophies should not be handed out by a distributive principle of ability to pay. This would be an illegitimate form of distribution that would not respect the way in which sport is valued. If money can change the distributive principle of the sphere of sport, an injustice has occurred. The question still remains: how can money change the distributive principle of sport so that merit is not being used to allocate awards?

${ }^{89}$ Walsh and Giulianotti, Ethics, Money and Sport, 91. 
If a professional sports league has no restrictions on how much money a team can spend on its players, the teams with the wealthiest owners would have the best chance to attract the best players. If you can attract the best players, you have a much better chance at winning. In Major League Baseball, the professional baseball league in the United States, there is no salary cap. Teams are actually allowed to spend as much money as they want on players. In 2013, the highest payroll was the New York Yankees, who had a payroll of $\$ 228,835,490$. The team with the lowest payroll was the Houston Astros, who had a payroll of $\$ 22,062,600 .{ }^{90}$ How is a team that pays its players less than $10 \%$ of what its competitor pays its players supposed to compete? The answer is pretty clear: they cannot. In the past 10 years, not a single team outside of the top 12 in total payroll has won the World Series. ${ }^{91}$ Further, only two teams with a below average payroll have even appeared in a World Series in the last 15 years. ${ }^{92} \mathrm{~A}$ team in the MLB cannot win unless it has a high payroll. This is a clear case of the money changing the distributive principle of sport from merit to ability to pay. Interestingly, this can be thought of either as an inequality issue or a corrosion issue. It can be framed as an equality issue because wealth is becoming even more influential and is now determining who wins

\footnotetext{
${ }^{90}$ MLB Team Payrolls. http://www.stevetheump.com/Payrolls.htm ${ }^{91}$ ESPN, "MLB World Series Winners." http://espn.go.com/mlb/worldseries/history/winners, Orinick, Steve. MLB Team Payrolls http://www.stevetheump.com/Payrolls.htm

${ }^{92}$ Matthew Lamar. "Royals, Giants bucking recent payroll trends with World Series appearance." SB Nation Royals Review, October $20^{\text {th }}, 2014$. http://www.royalsreview.com/2014/10/20/7010007/royals-giants-buckingrecent-payroll-trends-with-world-series
} 
sporting events, or it can be framed as a corrosion issue because market norms are corroding the values of sport.

This is worrisome. Money should not determine who wins. This is a violation of the way we value sport and the goods associated with sport. Luckily, there are ways to avoid this. All of the major leagues in North America have a draft system that means each team has a relatively equal chance of signing the best new professional players. Even better, the drafts are actually designed so that the teams that were the worst in the previous year have a better chance of landing a high draft pick, which would secure the rights to a better incoming professional player. This is a clear step in the right direction. Most leagues in North America also have a salary cap. This limits the amount of money that teams are allowed to spend on players, and has the effect of decreasing the effect of money in the sphere of sport. With hard salary caps and well-designed draft systems in place, the positive effect of commodification (increased viewership) remains and the negative effects are limited if not fully eliminated.

The fourth critique that Walsh and Giulianotti level against the commodification of sport is closely connected: they argue that commodification of sport will lead to the downfall of sport in the long term, and their critique is centered on lopsided competition and certainty of outcome. Whether or not this is a legitimate worry remains to be seen. But, by putting in place salary caps and welldesigned amateur drafts, we can immediately quell the worry of this critique. There is no reason to discuss it further. 
Of the four possible moral pathologies that Walsh and Giulianotti identify, I have shown two - that commodification illegitimately changes our motivation structure and that commodification leads to treating athletes as mere means - to be unfounded. The rejection of these critiques also led to a rejection of the worry that the goods of sport might be the sort of goods whose value cannot be realized when paid for or governed partially by the norms of the market. Of the remaining two critiques by Walsh and Giulianotti, one of them is a serious worry. By explaining this critique in a Walzerian framework, we can see that there is a very real possibility that the commodification of sport can lead to the distributive principle being unjustly changed from merit to ability to pay. In fact, we see a real world example of this happening, in Major League Baseball. However, we also see that other professional sports leagues in North America have taken this worry seriously and have limited the effect that money can have on their sport. This should be taken as an example for all professional sports leagues, and policies should be put in place to make sure commodification does not corrupt the sphere of sport.

Walsh and Giulianotti aimed to show that we should be very worried about the commodification of sport. In the end, though, the worries that they identify do not actually happen in professional sport and so have no weight. Professional sports viewership is extremely high, and athletes are being given the opportunity to make a real living while playing the games they love. My goal in this chapter was to show that the non-commodification claim that is at the basis of the Principle of Amateurism is indefensible, and I have now done this. Because the claim turns out 
to be indefensible, the NCAA cannot legitimately use it to restrict student-athletes from being paid. The fact that they continue to use it will become important in Chapter Four. 


\section{Chapter Three Examining Theories of Exploitation}

So far, two initial goals have been accomplished: in Chapter One, the landscape of American college athletics was introduced. The relevant facts (including the relevant legal cases) were presented, and a brief attempt was made at explaining some of the implications those facts might have. In Chapter Two, I argued that the moral claim behind the NCAA's Principle of Amateurism - namely the claim that sport should not be commodified - is at best a questionable moral claim. At worst, it is indefensible. I have said little so far about how the NCAA's application of the moral claim affects the claim about exploitation. This is an issue that will come up in Chapter Four. Up to this point, the main question that this project aims to answer - are student-athletes in the NCAA exploited? - has not been answered. It is in this chapter that I will begin to examine this issue more closely. To know if student-athletes in the NCAA are exploited, we first must know what it means to be exploited. In this chapter, I will examine a number of different theories of exploitation. I will begin by looking at contemporary Marxist accounts of exploitation, particularly the one offered by Richard Arneson. From there I will move to the contemporary Kantian account offered by Allen Wood, and then finally to transactional accounts put forward by Robert Goodin and Alan Wertheimer. At the end of the chapter, I will argue that we can best understand the exploitation that is happening in American college athletics (and indeed exploitation in general) by using Alan Wertheimer's account. 
Throughout the chapter, I will be referring back to four cases of possible exploitation. They are as follows:

1. That a lifeguard exploits a drowning man when he demands $\$ 20,000$ before he will save his life.

2. That an umbrella salesman exploits his customers when he triples his prices during a particularly bad rainstorm;

3. That a company exploits a sweatshop worker in Indonesia when they make him work in bad conditions for very low wages.

4. That NCAA schools exploit their student-athletes.

I will be assuming throughout the chapter that a good theory of exploitation should be able to deal with and explain our intuitions that each of these cases involves exploitation.

\section{I}

In his 1981 paper What's Wrong with Exploitation? Richard Arneson interprets the normative content in Marx's claims about exploitation. The first thing that Arneson does is differentiate between technical exploitation and wrongful exploitation. ${ }^{93}$ He notes that in Marx's texts there is a clear economic meaning of the term exploitation, but that these texts do not clearly delineate the moral significance of exploitation (thus the paper title, What's Wrong with Exploitation?). Arneson

${ }_{93}$ Richard Arneson. “What's Wrong with Exploitation?” Ethics 91 (1981): 203. 
defines that technical sense of the term as appropriation by a class of non-workers of the surplus product of a class of workers. ${ }^{94}$ In a systemic account like the Marxist one, exploitation does not have to do with an individual transaction between a worker and an employer, but rather with the system that is in place that allows for those types of transactions to occur. A society has exploiters and those who are exploited, and exploitation is the continuous transfer of surplus value from the exploited to the exploiters. As John Roemer helpfully points out, it isn't that ' $A$ exploits $B$,' but rather ' $A$ is an exploiter' and $B$ is 'exploited.'"95 These are direct features of their class membership.

This is the very basis of any modern-day wage work: If I hire someone to run my business for $\$ 30 /$ hour, and the total amount of money I make for every hour that person works is $\$ 50$, then I expropriate the surplus of $\$ 20$ that remains after I pay my worker. This is technical exploitation on a Marxist framework, and in this scenario I am an exploiter and the person I hire is exploited. This technical sense of the word does not reflect our everyday use of the term. When we use the term exploitation in everyday speech, we use it as a normatively significant term: if you say that factory workers in Southeast Asia are being exploited you are making an economic statement of fact, and you are claiming that they are being wronged in some significant way, and usually we think that harm comes specifically from the exploiter.

\footnotetext{
${ }^{94}$ Arneson, "What's Wrong with Exploitation?" 203.

95 John Roemer. "Should Marxists be Interested in Exploitation?" Philosophy \& Public Affairs 14 (1985): 31.
} 
Arneson argues that for Marx wrongful exploitation happens anytime that technical exploitation happens and the following two criteria are met: one, "the nonworkers have vastly more social power and they employ this power to bring about technical exploitation;"96 and two, "this technical exploitation establishes an extremely unequal distribution of economic advantages and it is not the case that one can distinguish the gainers from the losers in terms of greater deservingness." 97 The first criterion plays a particularly strong role in almost all Marxist exploitation literature. Arneson defines social power as the ability to get others to do something that benefits you without the use of persuasion. ${ }^{98}$ What he is getting at here is ownership of land or ownership of what Marxists call "the means of production." John Roemer, for instance, argues that the most compelling argument for a normative Marxist account of exploitation is differential ownership of productive assets. According to Roemer, exploitation can be thought of as having to do with an initial inequality of assets. From this inequality of assets, certain groups of people do little work and receive social and financial profit, while other groups do more work and receive less social and financial profit.99

Iris Marion Young follows the same line of thinking: exploitation involves the continuous transfer of the results of the labour of one social group to benefit another social group. ${ }^{100}$ Through private ownership of the means of production (or domination of capital), "capitalism systematically transfers the powers of some

\footnotetext{
96 Arneson, "What's Wrong with Exploitation?" 212.

97 Arneson, "What's Wrong with Exploitation?" 212.

98 Arneson, "What's Wrong with Exploitation?" 212.

99 Roemer, "Should Marxists be Interested in Exploitation?" 52. 100 Iris Marion Young,. Justice and the Politics of Difference, (Princeton: Princeton University Press, 2011), p. 48.
} 
persons to others, augmenting the power of the latter."101 This systemic transfer of power (as profit) from one group to another is exploitation. Despite formal freedom and the ability to freely contract and receive a wage, Young argues that capitalist society inevitably results in one class dominating another class. This, she argues, is because capitalist society is inherently exploitative. ${ }^{102}$ Arneson's first criterion for wrongful exploitation on a Marxist framework - that the non-workers have vastly more social power and they employ this power to bring about technical exploitation - is a criterion about ownership of productive assets, or domination of the means of production.

In the second criterion, though, Arneson is arguing that inequalities in economic distribution can be fair and not wrongfully exploitative if the inequalities are a result of the two parties in some way deserving to receive different amounts. We will call this the moral desert criterion. According to this criterion, it might be possible for there to be technical exploitation without there being wrongful exploitation. If, for instance, somebody begins life with next to nothing, has few marketable talents, works extremely hard in order to develop socially valuable talents, ends up owning land and technically exploiting others, it seems that this might not be wrongful exploitation. The person's financial success and ownership of productive assets is entirely due to the fact that he has worked tirelessly to achieve this. He deserves, due to his hard work to develop socially valuable talents, all of his assets.

101 Young, Justice and the Politics of Difference, 49. 102 Young, Justice and the Politics of Difference, 49. 
However, Arneson goes on to argue that every case of technical exploitation that has actually occurred thus far in the world has also been a case of wrongful exploitation because unequal distribution of economic advantages is never due to greater deservingness. ${ }^{103}$ As Arneson points out, original appropriation of land in capitalist societies has always been by force. There has never been an initially just distribution of land or resources, and so any distributive sequence that follows and involves technical exploitation has been wrongfully exploitative. ${ }^{104}$

If we take the broad systemic view to be the correct one, it could certainly explain the statement that student-athletes in the NCAA are wrongfully exploited. It is definitely the case that schools appropriate the surplus value that studentathletes create from their work; it is definitely the case that schools have vastly more social power than any individual student-athlete; and, it is also true that the difference in economic reward between the school and the student-athlete has nothing to do with deservingness. It seems pretty reasonable to say that according to Arneson, Young's, and Roemer's account of Marxist exploitation, student-athletes in the NCAA are wrongfully exploited.

However, the result of this view is that any wage-labour in a capitalist society is both technically and wrongfully exploitative. This does not quite seem to capture the way we use the term exploitation in many contexts. Certainly it might capture the way that we say a sweatshop worker in Indonesia is exploited, but it would seem strange to say that an executive for an investment company who makes six figures but whose company still expropriates the surplus value of his or her work is

103 Arneson, "What's Wrong with Exploitation?" 209.

104 Arneson, "What's Wrong with Exploitation?" 210. 
exploited in the same way. Further, it does not capture the nuance of the term in the way that we might use it to say that an umbrella salesman exploits a consumer when he triples his prices during a particularly bad rainstorm, or the way we might use the term to say a drowning man is exploited when a lifeguard demands $\$ 20,000$ before saving him.

Nonetheless, much of the contemporary discussion of exploitation draws on concepts that are present in Arneson's examination of Marx. When Arneson points to power-inequality being a key factor in wrongful exploitation, ${ }^{105}$ when he states that "exploitation is roughly a matter of being taken advantage of by someone who has power over you,"106 or when he states that "exploitation is not simply a distributional concern,"107 he is drawing out important parts of Marxist literature that continue to inform contemporary discussion of exploitation, even outside of Marxist circles. ${ }^{108}$ If we go back to the umbrella salesman, just as an example, we can see a lot of these ideas at play: there is a power imbalance between the salesman and the customer due to the rainstorm; the salesman is taking advantage of the power imbalance; and finally the nature of the exploitation has to do with something other than distributional outcomes or concerns. All of these things are true in the case of the umbrella salesman exploiting the customer during a rainstorm, and yet it is not the case that expropriation of surplus value or wage-work has any role to play in explaining the exploitation. So, we have a situation that we might want to say is

\footnotetext{
105 Arneson, "What's Wrong with Exploitation?" 224.

${ }^{106}$ Arneson, "What's Wrong with Exploitation?" 224.

${ }^{107}$ Arneson, "What's Wrong with Exploitation?" 224.

108 The same can be said of Arneson's discussion of the role that coercion plays in Marx's conception of exploitation.
} 
wrongfully exploitative, but that has nothing to do with technical Marxist exploitation. Let us continue our discussion by moving on to Kantian exploitation.

\section{II}

Allen Wood, in his paper Exploitation, argues for an understanding of exploitation that is deeply rooted in Kant. In Chapter Two I briefly discussed Kant's Formula of Humanity of the Categorical Imperative. Kant argues that it is always wrong to treat others as mere means, and that when we do so we are failing to show proper respect for the humanity of others. Importantly, the Formula of Humanity does not require that we never use others as a means to our end, but that if we do so we must also be respecting them as an end in themself. ${ }^{109}$ For instance, it is not wrong for me to take a taxi to get to my workplace. Even though I am treating the taxi-driver as a means to my own end, I am consistently treating him as an end in himself as well. The fact that taxi-driver is exercising his will and his rational capabilities in agreeing to take me to my work in return for a fare means that I have treated him as an end, even though I have also treated him as a means to my own end. ${ }^{110}$

Wood argues that what is morally troubling about exploitation is that it constitutes a violation of the Kantian norm which he believes we all endorse, which is that "proper respect for others is violated when we treat their vulnerabilities as

${ }^{109}$ Kant, Immanuel. Groundwork for the Metaphysics of Morals.

110 Robert Johnson, "Kant's Moral Philosophy," The Stanford Encyclopedia of Philosophy http://plato.stanford.edu/entries/kant-moral/\#HumFor. 
opportunities to advance our interests or projects." 111 He goes on to say that it is degrading to have our weaknesses taken advantage of and that is dishonorable to take advantage of others for personal advantage. ${ }^{112}$ Not unlike systemic theorists, he differentiates between what exploitation technically means, and what the moral harm of exploitation is. For Wood, the term exploitation means taking advantage of or using others in order to benefit ourselves, and the moral harm associated with exploitation is that we do not show proper respect for others (we do not treat them as ends in themselves) when we exploit them.

Wood argues that in fact the moral belief he is ascribing to many of us is stronger than the Kant's Formula of Humanity. As I mentioned earlier, we can consistently treat others as ends in themselves while still using them to our advantage. We likely do so if an exchange is mutually advantageous and consented to by the other party, even if I use the other person as a means to my end. Wood argues that even in cases where consent is given and the other person benefits, we can still be violating the moral norm associated with exploitation by taking advantage of another's vulnerability. So, cases that would not violate Kant's Formula of Humanity would still violate the moral belief that Wood argues is both widelyheld and explains the moral content of exploitation. ${ }^{113}$

In Wood's discussion of what he terms "capitalist exploitation," we begin to see that Wood's account is missing something critical. Wood asks whether Marxists theorists were right in saying that wage labour is inherently exploitative. He argues

111 Allen Wood. "Exploitation,” Social Philosophy and Policy 12 (1995): 150-151.

112 Wood, "Exploitation," 151.

113 Wood, "Exploitation," 151. 
that because of the fact that owners of the means of production have a distinct position of bargaining power over labourers, this creates a vulnerability for the workers. For owners of the means of production to take advantage of this vulnerability, Wood argues, is failing to show proper respect for the workers. ${ }^{114}$ Here, Wood has identified something that I will discuss at further length later in the chapter, which is that an inequality in bargaining power often leads to exploitative transactions.

But it is not clear that transacting with somebody who is in a position of weak bargaining power is failing to show proper respect for them. While we might think that we should improve background conditions so that fewer people hold positions of bargaining weakness, we might also think that offering terms of employment to those who need employment and to people who are exercising their will and rational capability in deciding to accept the terms of employment is entirely in keeping with showing proper respect for others. This points to a general weakness in Wood's framework: he identifies issues that are closely related to and often involved in cases of exploitation, but his framework does not properly explain many cases of exploitation.

While it may well be the case in cases of severe exploitation that I do not show proper respect for the person with whom I transact, I do not think this is what is wrong with exploitation in all cases. While certainly we can say the lifeguard fails to show proper respect for the drowning man when he demands $\$ 20,000$ before he will save him, Wood's conception of exploitation does not explain the other cases.

114 Wood, "Exploitation," 155. 
Does the umbrella salesman fail to show proper respect for others when he raises his prices during a terrible rainstorm? It is not clear that he does. An umbrella salesman makes his living by taking advantage of the fact that people need umbrellas. The fact that this need is heightened during a rainstorm is an opportunity for him to improve his profits. Importantly, though, the purchaser still has a choice. If he thinks the price is too high, he can choose not to buy the umbrella. If we say the umbrella salesman fails to show proper respect for others when he increases his price during a bad rainstorm, but that he shows proper respect when he takes advantage of the general fact that people need umbrellas, we commit ourselves to a strange view. At some specific point between the normal price during dry conditions and the increased price during a bad rainstorm, the umbrella salesman suddenly goes from showing proper respect to failing to show proper respect even though he is taking advantage of the same fact, which is that people have a need for umbrellas. Instead of doing this, we should say that he does not fail to show proper respect. The umbrella salesman can simultaneously increase his price with the increase in demand and show proper respect for his customer. ${ }^{115}$

Perhaps more importantly, does a company that runs a sweatshop in Indonesia fail to show proper respect for others when it offers terms of employment to somebody who has no better options? Again, this is not immediately clear. As I argued above, we might think that offering employment to somebody who has no

115 The situation would become different if he were a salesman of a good that was required for survival during a particular time. A lifeboat salesman during a bad flood, for instance, would be failing to show proper respect for others if he drastically increased his prices. 
better options is entirely in keeping with showing proper respect for others. ${ }^{116}$ Lastly, it certainly it does not seem that a university fails to show proper respect for a student-athlete when it offers him a full scholarship in return for his athletic services. By allowing a potential student-athlete to play the sport he or she loves while getting an education, it seems that schools are entirely in keeping with showing proper respect for student-athlete. Despite the fact that Wood's view struggles with these last three cases, we have strong intuitions that people are exploited.

So, while I think many cases of exploitation might happen to involve not showing proper respect for others, this is not what is fundamentally wrong with exploitation. Rather than identifying the particular moral harm that occurs in all cases of exploitation, Wood has identified a moral harm that is often present in cases of exploitation. But, his framework cannot adequately explain some cases about which we have strong intuitions that exploitation has occurred. Let's move on to transactional approaches to exploitation, which I will argue can better account for our intuitions about different cases of exploitation.

\section{III}

A transactional account claims that exploitation involves some sort of wrong in an individual transaction between two (or more) people. So, it is not the case that $A$ is an exploiter and $B$ is exploited, but rather that $A$ exploits $B$. All transactional

${ }^{116}$ And note, we can do this while still saying that it is wrong in some way that the man has no better options for employment. 
exploitation theorists agree that exploitation involves taking unfair advantage of another person: $A$ exploits $B$ when $A$ takes unfair advantage of $B$. What exactly it means to take unfair advantage is where theorists disagree.

Robert Goodin claims that an act of exploitation is entirely contextdependent: there is nothing intrinsically exploitative about an act. ${ }^{117}$ Contrary to both Marxist and Kantian views, a certain act could be exploitative in one scenario and non-exploitative in another. The background conditions against which an act is performed determine whether or not a given act is exploitative. Goodin claims that there are certain situations that make it inappropriate to "play for advantage," or have personal gain as your primary objective. It is when one does this - has personal gain as his or her primary objective in situations where it is inappropriate to do so - that an act of exploitation occurs. ${ }^{118}$ Goodin argues that there are four types of situations (in modern societies) in which it is inappropriate to play for advantage.

Let us delve deeper into this. First, it is wrong to play for advantage against others who have themselves renounced playing for advantage. ${ }^{119}$ Here, Goodin is primarily talking about personal relationships. In a personal, caring relationship, it seems entirely inappropriate to have personal gain as your primary objective. The idea of betraying one's trust is key to this notion. Also in this category is playing for your individual advantage in a group that is in some way playing for the advantage

117 Robert Goodin. Reasons for Welfare: The Political Theory of the Welfare State. (Princeton: Princeton University Press, 1988), 143

118 Goodin, Reasons for Welfare, 144.

119 Goodin, Reasons for Welfare, 145. 
of the collective. ${ }^{120} \mathrm{An}$ example here is a member of a team lazes about as he watches his teammates work extremely hard in pursuit of a common goal, and then reaps the (social, financial) advantages of the team's success.

Second, it is wrong to play for advantage against those who are unfit or otherwise unable to play in games of advantage at all.121 Here, Goodin argues that it is exploitative - not just dishonest - to cheat a blind man. Another example, claims Goodin, is that dieters might be exploited by grocery stores that set up displays of chocolate near the checkout counters; the grocery store is preying upon the dieter's weakness of will. The last example he gives in this category is of the lifeguard who demands a large sum of money from a drowning man before he will throw him the life preserver. ${ }^{122}$ Theorists have often used this type of example in order to claim that coercion or low quality of consent is always present in acts of exploitation. The advantage of Goodin's explanation is that it links the two but does not go as far as to say that all acts of exploitation involve coercion or low quality of consent.

Third, Goodin claims that it is wrong to play for advantage against other players who are no match for you in games of advantage. ${ }^{123}$ This is a link that Goodin thinks many theories of economic exploitation rely on: in situations involving disproportionate bargaining power it is inappropriate for the strong to press their advantage on the weak. Here, Goodin uses the example of a monopoly provider of some important commodity, or the monopoly buyer of a good that

120 Goodin, Reasons for Welfare, 145.

${ }^{121}$ Goodin, Reasons for Welfare, 145.

122 Goodin, Reasons for Welfare, 145.

123 Goodin, Reasons for Welfare, 146. 
somebody has to sell using his advantage to buy or sell at an unfair price. ${ }^{124}$ Interestingly, Goodin is not the only theorist to key in on monopolies as potentially problematic; Roemer and Arneson both talk about monopolies often leading to exploitation, and - as I will show later - Wertheimer's framework could also include monopolies as possibly leading to exploitation.

This is an important and overlooked overlap between systemic and transactional accounts of exploitation, which are broadly distinct approaches. That both of types of accounts mention monopolies as often leading to exploitation points to something very fundamental about exploitative transactions: it is not that monopolies are wrong in and of themselves, but that the presence of a monopoly almost guarantees unequal bargaining power between two parties. The belief that we should restrict monopolies, which is supported by the fact that there are laws restricting monopolies and price-fixing, is based upon a belief that monopolies limit the autonomy of individuals by restricting options and thereby undermining bargaining power. This point about monopolies will become important again in Chapter Four.

The last general type of situation in which it is wrong to play for advantage occurs when your relative advantage comes from the grave misfortunes of another. ${ }^{125}$ This is meant to be a distinct category from the coercion or quality of consent category. Here, Goodin has in mind inappropriate use of the grave misfortunes of others: imagine a news crew using a long shot of a desperately grieving mother whose children have just died, or a circus parading around the man

124 Goodin, Reasons for Welfare, 146. 125 Goodin, Reasons for Welfare, 146. 
with a unique and grotesque disease. Goodin claims that even if the mother or diseased man were nicely compensated, they have still been exploited. ${ }^{126}$

Goodin clearly states that he does not think the list of categories is a comprehensive one. Instead, they are situations that come up often enough in modern society. Goodin thinks that all of the four on that list have one thing in common. In each scenario, the person doing the exploiting is violating the same moral norm: namely, the moral norm of protecting the vulnerable. ${ }^{127}$ This duty of care places a moral imperative on us to protect the interests of those who are vulnerable to us, regardless of what the source of their vulnerability is. So, exploitation is a violation of the moral norm of protecting the vulnerable. This moral norm has two parts, argues Goodin. The first is a duty to suspend ordinary rules of behavior and interaction when dealing with particularly vulnerable people to make sure that we do not take advantage of them. The second is a duty to actively assist in making them less vulnerable. ${ }^{128} \mathrm{~A}$ violation of only the second part of the norm is not exploitation, but a violation of the first is. ${ }^{129}$

Note the similarities between Goodin's view and Wood's. While Goodin's view is less obviously grounded in Kant, there are still similarities. Wood argued that taking advantage of a vulnerability was failing to show proper respect, and that is the moral content of exploitation. Goodin argues that there is a moral norm that requires us to suspend ordinary rules of behavior when interacting with particularly vulnerable people. Like Wood, Goodin's focus on vulnerability points to the

126 Goodin, Reasons for Welfare, 147.

127 Goodin, Reasons for Welfare, 147.

128 Goodin, Reasons for Welfare, 149.

129 Goodin, Reasons for Welfare, 149. 
presence of unequal bargaining power in cases of exploitation. And, like Wood, Goodin has identified something that might be present in many cases of exploitation, but, I will argue, does not adequately explain all cases of exploitation.

For Goodin, the biggest issue has to do with the focus on vulnerability. Certainly we can say that the drowning man is vulnerable, and that the lifeguard who is demanding $\$ 20,000$ from him is taking advantage of that vulnerability in a morally objectionable way. We can also safely say that the sweatshop worker in Indonesia is vulnerable in a morally significant way, and that the company for whom he works is taking advantage of that vulnerability. Interestingly, though, even if we think that even the company is taking advantage of his vulnerability, the solution might not be to stop the company from doing so. The moral harm does not seem to be that the company is offering terms of employment to a man that has no better options, but rather that the man has no better options in the first place.

Goodin's framework leads to a bizarre situation: the company is doing something wrong by offering terms of employment to the sweatshop worker, but you and I, by avoiding interaction with the man, are clear of any wrongdoing. Further, using Goodin's framework would mean that by withdrawing terms of employment to the sweatshop worker, the company is doing a good thing by avoiding exploitation. So, while we might think that Goodin's framework can explain the transaction between the sweatshop worker and the company he works for as exploitative, we might also think that it leads us to the wrong conclusions about what we should do about the exploitation. 
Goodin's framework runs into further problems with the umbrella salesman example. It is here that the broad and unclear nature of the term vulnerability is called into question. Is the person who wants to buy an umbrella when he is caught in a rainstorm vulnerable? If he is, this would create a question about how many people count as vulnerable and what the moral significance of vulnerability is. There are two options: one, the person wanting to buy an umbrella is not vulnerable and Goodin's framework fails to explain this case of exploitation; or two, he is vulnerable and vulnerability becomes so broadly defined that the moral significance of a claim about vulnerability becomes quite small. Even if the the man caught in the rainstorm does count as vulnerable, we would want to say that his vulnerability is morally insignificant in comparison to the vulnerability of the sweatshop worker. And, even if the umbrella customer is vulnerable, we might want to say that Goodin's norm of protecting the vulnerable does not apply in all cases of vulnerability. Certainly the norm should not apply equally to both the sweatshop worker and the man caught in a rainstorm.

Most importantly to my project, Goodin seems to entirely miss the mark when it comes to explaining the exploitation that might occur in college athletics. To say that the NCAA is taking advantage of a vulnerability by offering potential student-athletes a free education does not match our considered intuition about what the nature of exploitation is in college athletics. Our intuition is not that student-athletes are in vulnerable in some morally significant way, but rather that the NCAA is acting unfairly by stopping student-athletes from receiving a fair share of the revenue they help to create. 
So, it turns out that Goodin's framework runs into trouble with three of the examples of possible exploitation. While he is able to explain the exploitation in the case of the lifeguard exploiting a drowning man, his view leads us to wrong conclusions or cannot explain our intuitions about exploitation in the other three cases.

\section{IV}

Alan Wertheimer, in a strong departure from Goodin's or Wood's framework, makes very specific stipulations about what makes a transaction exploitative. He usefully distinguishes between the two parts of a transaction that might have to do with exploitation. The first pertains to the outcome of the transaction and the second to the process by which the transaction was entered into. ${ }^{130}$ In terms of the outcome of the transaction, there are two elements to consider: namely, the benefit to $A$, and the effect on $B$. It might be the case that it is unfair for $A$ to benefit at all from the transaction because he has harmed $B$ in the transaction; or it might be the case that it is unfair for $A$ to benefit to the extent that he does in comparison to the benefit that $B$ receives. Now, if we think that $A$ taking unfair advantage of $B$ has something to do with the process, we are making a claim about the quality of $B$ 's consent. It could be that $A$ has coerced $B$, or simply that the quality of $B$ 's consent is less than it should be in a transaction. In either case, Wertheimer thinks that this means $A$ has taken unfair advantage of $B$.

\footnotetext{
${ }^{130}$ Alan Wertheimer. "Exploitation" The Stanford Encyclopedia of Philosophy. http://plato.stanford.edu/entries/exploitation/.
} 
Let's start by taking a closer look at outcomes. Wertheimer argues that the first condition that must be met for $A$ to take unfair advantage of $B$ is that $A$ must gain some actual advantage from his transaction with $B$; if $A$ does not gain an advantage, then it makes little sense to speak of $A$ taking advantage of $B$ whatsoever. ${ }^{131}$ If, however, $A$ has gained from the transaction, then we must talk about what has happened to $B$. Wertheimer argues there can be three outcomes for $B$ : first, $B$ can remain at his pretransaction status quo, meaning that $B$ is neither worse off nor better off for having transacted with $A$; second, $B$ can move below his pre-transaction status quo, meaning that $B$ is worse off for having transacted with $A$; third, $B$ can move above his pre-transaction status quo, meaning that $B$ is better off for having transacted with $A \cdot{ }^{132}$

Wertheimer is relatively uninterested with the first situation, and says that if $B$ remains at his pre-transaction status quo, then the transaction between $\mathrm{A}$ and $\mathrm{B}$ can be described as harmless parasitism. ${ }^{133}$ It might be that $A$ has taken advantage of $B$, but no harm has come of it, and so it does not really matter. If $B$ is worse off because of his interaction with $A$, then this is a clear case of harmful exploitation. The most interesting cases, however, are when $B$ actually becomes better off for having transacted with $A$. These can be called mutually advantageous transactions and, according to Wertheimer,

\footnotetext{
${ }^{131}$ Alan Wertheimer, "Exploitation in Clinical Research," in Exploitation and Developing Countries: The Ethics of Clinical Research, ed. Hawkins and Emanuel (Princeton: Princeton University Press, 2008): 69.

132 Wertheimer, "Exploitation in Clinical Research," 70.

133 Wertheimer, "Exploitation in Clinical Research," 70. Also, Wertheimer's claim that this is uninteresting is dubious. What he calls "harmless parasitism" is more harmful than mutually advantageous exploitation. This particular point of disagreement is, however, besides the point when it comes to the case of American college athletics.
} 
they can be either exploitative or non-exploitative. ${ }^{134}$ What makes a mutually advantageous transaction exploitative is when $A$ gains more than he should from the transaction or $B$ gains less than he should from the transaction as measured against what each would have received under ideal bargaining conditions. ${ }^{135}$

If a transaction is exploitative, yet both parties have agreed to it and gain from it, it is unclear what steps - if any - should be taken to make sure $B$ is not exploited. Here, Wertheimer wants to draw a line between exploitative transactions and transactions that should be interfered with. ${ }^{136} \mathrm{He}$ argues that if both parties have agreed to the transaction, both parties gain from the transaction, and no third party is made worse off by the transaction, then there is likely no defensible reason for interfering with the transaction. ${ }^{137}$ Although $B$ is being exploited, why should we stop this transaction from taking place? Both parties are agreeing to it, and both parties are gaining from it. Scenarios like this are instances of permissible exploitation, and they should not be interfered with. Wertheimer deems this the principle of permissible exploitation. ${ }^{138}$ So, by looking at outcomes we see that exploitative transactions can be of three sorts on Wertheimer's view: harmful, harmlessly parasitic, or mutually advantageous. What makes a given transaction exploitative is when $B$ gains less than he would under ideal conditions or $A$ gains more than he would under ideal conditions, and this applies to all three types of transactions. Often, $B$ gaining less than he should under ideal conditions will have something to do with the quality of

\footnotetext{
134 Wertheimer, "Exploitation in Clinical Research," 73-74.

135 Wertheimer, "Exploitation in Clinical Research," 74.

136 Wertheimer, "Exploitation in Clinical Research," 79.

137 Wertheimer "Exploitation in Clinical Research," 79.

138 Wertheimer, "Exploitation in Clinical Research," 82-83.
} 
B's consent. By looking at the process of a transaction (how the transaction was actually made), we find out what the quality of $B^{\prime}$ s consent is.

Let's take a closer look at the transactional process. In harmful exploitation, the quality of consent is likely to be quite low, whereas in mutually advantageous exploitation it will likely be higher. ${ }^{139}$ In his discussion of the process by which an exploitative transaction might occur, Wertheimer identifies two procedural defects that fully invalidate the consent of $B$ and thereby render a transaction harmfully exploitative. These are coercion and fraud. ${ }^{140}$ Coercion happens when $A$ threatens to make $B$ worse off if he does not transact with $A$. Coercion invalidates consent, which means that transaction is harmful. Fraud happens when $A$ misrepresents the transaction, so that $B$ 's consent is not informed. Valid consent must be informed, and so any exploitative transactions involving fraud lack valid consent and are thereby harmful. Exploitative transactions that involve coercion or fraud are harmful, and their moral force is strong. ${ }^{141}$

Wertheimer also identifies other possible scenarios that could invalidate consent, but not to the extent that coercion and fraud do so. In his SEP entry, Wertheimer argues that there are certain cases that might not involve coercion or fraud, but that would still drastically increase the moral force of the exploitative transaction. Wertheimer essentially argues is that if $A$ has played a direct causal role in creating the circumstances that lead to exploitation, we are dealing with exploitation that has a much stronger moral force. Unfortunately, Wertheimer does

${ }^{139}$ Alan Wertheimer, "Exploitation" The Stanford Encyclopedia of Philosophy. http://plato.stanford.edu/entries/exploitation/, ${ }^{140}$ Alan Wertheimer, "Exploitation” The Stanford Encyclopedia of Philosophy. ${ }^{141}$ Alan Wertheimer. "Exploitation" The Stanford Encyclopedia of Philosophy. 
not recognize the importance of this criterion when assessing college athletics - a failure I will discuss in Chapter Four.

To quickly sum up Wertheimer's theory, a transaction is exploitative if $B$ receives less than he would in an ideal world, but an exploitative transaction does not necessarily hold adequate moral force to warrant interference. If both parties agree to a transaction and both parties gain from the transaction, the moral force of the exploitation is quite weak and we have do not have good enough reason to interfere with it. Such transactions are examples of mutually advantageous exploitation. If, however, $A$ has acted fraudulently or coercively in order to get $B$ to agree to the exploitative transaction, then the moral force is much stronger and we have good reason to interfere with the transaction. These transactions are harmfully exploitative transactions.

Wertheimer's view is a good one to move forward with for a number of reasons. First, it keeps intact the general idea that exploitation has something to do with economics. We can apply Wertheimer's framework to a broad variety of potentially exploitative cases - be it a sweatshop worker in Indonesia, an umbrella salesman increasing prices during a storm, a lifeguard who demands money from a drowning man, or student-athletes in the NCAA. And, his view can apply to all of these cases without the downfalls of the systemic view. The second major advantage is that Wertheimer readily admits - and even gives ways for analyzing - that different cases of exploitation can have different moral forces. If an umbrella salesman exploits a wealthy businessman, we are probably less concerned than we would be if a company like Nike makes its workers in Indonesia work in dangerous 
conditions for a small wage. By differentiating between the truth conditions for an exploitative transaction and the factors that make up the moral force of an exploitative transaction, Wertheimer's framework is both precise and flexible at the same time.

The one major drawback is being able to determine what a "fair" price for a transaction is. Whether or not a transaction is exploitative has to do with whether or not the two parties in a transaction receive what they would receive under ideal bargaining conditions. Often, a person will not receive as much for their labour as they would otherwise because they have a weak bargaining position. This means they are exploited. But, what exactly does it mean for there to be equal bargaining conditions? How do we determine the price that would be agreed upon under these bargaining conditions? These are serious questions, and ones that point to a weakness in Wertheimer's framework. However, this is likely an issue for the cases of exploitation that have a weaker moral force. If an exploitative transaction has a strong moral force, it is likely that the bargaining position of one the parties is obviously and significantly inferior and that the agreed upon price is therefore obviously unfair. So Wertheimer's framework might struggle to identify the cases of exploitation that are weak cases, but it does not struggle with the more morally significant ones. ${ }^{142}$

142 Interestingly, I think there is some overlap between Wood's, Goodin's, and Wertheimer's approaches. When Wertheimer claims that the moral force of a transaction is stronger when someone's consent is weaker due to a poor bargaining position, this could be explained in terms of not showing proper respect for others or in terms of taking advantage of vulnerability. The advantage that Wertheimer has is that he does not have to explain it this way. 
In the remaining chapters of this thesis, I will use Wertheimer's theory of exploitation to examine whether or not student-athletes in the NCAA are exploited. I do not claim to have shown in this chapter that Wertheimer's is the only legitimate theory to judge the NCAA by, but I do hope to have shown that the other theories have serious enough issues that make them less attractive. Further, I do not claim to have fixed the major issue with Wertheimer's theory, but I hope to have shown that the issue with his theory is not as important in cases of morally strong exploitation, and that this issue is not as serious as the issues with other conceptions of exploitation. 


\section{Chapter Four A Critique of Wertheimer's View on College Sports}

So far, three of the five goals that I initially set out have been achieved. In Chapter One I introduced the topic and showed why it was worthy of philosophical inquiry; in Chapter Two I argued that despite arguments to the contrary from Walsh and Giullianoti, there is nothing wrong with money being involved in sport (so long as we counteract the possible issue of being able to buy wins); and in Chapter Three I argued, after expositing his and other theories of exploitation, that Wertheimer's theory of exploitation is the one we should be using. I argued that not only is it the best way to understand the statement that student-athletes in the NCAA are exploited, but it also has advantages overall as a theory of exploitation. In this chapter, I will take a closer look at Wertheimer's application of his own theory to the case of college athletics. I will identify and discuss two mistakes that Wertheimer made in his own investigation of this case that led him to the wrong conclusion that these transactions are not wrongfully exploitative. I use the word mistake because I believe that Wertheimer's theoretical framework is the right one, but that he made mistakes in applying the theory to the case of American college athletics.

The first error is outcome-related, namely that he underestimates how many schools exploit their student-athletes. The second error has two parts, and is process-related. Wertheimer's chapter on college athletics focuses almost entirely on the outcome of transactions, but his own theory clearly states that the process by which a transaction comes about can be very important in determining the moral force of a possibly exploitative transaction. The first part of this error is that he fails 
to recognize universities are acting fraudulently; the second part is that he fails to recognize schools are acting coercively. The combination of fraud and coercion allows schools to create the circumstances that allow them to deny pay to their student-athletes. Given the importance of fraud and coercion in his own theory, this process-related mistake in particular is very important. These two errors, taken together, lead Wertheimer to a wrong conclusion about the breadth and moral force of the exploitation in American college athletics. I will argue that based on Wertheimer's own theory, focusing both on outcome and on process, studentathletes in the NCAA are harmfully exploited by their schools, albeit some more than others. Please note that there will be times throughout the chapter that I go over material that was originally brought up in Chapter One. This material is particularly important to the argument in this chapter.

In applying his theory to the case of student-athletes in the NCAA, Wertheimer argues that student-athletes might be exploited by their schools, but that this is mutually advantageous - rather than harmful - exploitation. ${ }^{143}$ Wertheimer claims that only schools whose athletics departments generate a surplus can be thought of as exploiting their student-athletes. He is clear that to exploit, one must gain from the transaction. His argument here is that only schools whose athletics departments create a surplus can be thought of as gaining from the transaction with their student-athletes. ${ }^{144}$ Wertheimer argues that even these

${ }_{143}$ Alan Wertheimer, Exploitation. (Princeton: Princeton University Press, 1996), 95. 144 Wertheimer, Exploitation, 79. He also presents a slightly different rebuttal, one against those who argue that the alleged exploitation of the NCAA does not have to 
schools do not wrongfully exploit any of their student-athletes, because it is mutually advantageous.

While he says that there are some student-athletes that receive less from the transaction than they would under ideal bargaining conditions, he argues that the schools are simply taking advantage of an existing power imbalance that is caused by the fact that we live in a less than just world. ${ }^{145}$ If we lived in a more just world, he argues, it is likely that post-secondary education would be (at least) more affordable. This would mean that fewer students would feel pressured to play college sports in order to pay for their education, and the NCAA would not be in a position to deny pay to those deserving of it. ${ }^{146}$ What is crucial here is his distinction between taking advantage of an existing injustice and creating an injustice in order to take advantage of it. The former does not make for harmful exploitation, but the latter might. Wertheimer argues that the college athletics case is of the first sort, and therefore not harmfully exploitative. ${ }^{147}$

do with unfair outcomes. I am uninterested in this line of argumentation in this paper because it is not the argument that I am making with in this paper.

145 Wertheimer, Exploitation, 95.

146 Wertheimer, Exploitation, 95.

147 Wertheimer, Exploitation, 95. In his chapter, Wertheimer takes into consideration as possible evidence a number of things that might change his conclusion. For instance, he speaks about amateurism as an ideal and what the effects would be if amateurism is a not a worthwhile moral ideal. In the end, though, he concludes that the case is mutually advantageous exploitation, and so dismisses the possible evidence to the contrary. Further, he interestingly makes the claim that society at large might be harmfully exploiting student-athletes by not fixing the background conditions that allow for NCAA schools to exploit them in a mutually advantageous way. 
In the remainder of this paper, I intend to show that Wertheimer's conclusion regarding exploitation and college athletics is wrong: not because his theory is a bad one, but because he makes two crucial mistakes in applying his theory to the case of the student-athletes in the NCAA. The first mistake has to do with his assessment of the outcome of the transaction, and the second mistake has to do with his assessment of the process by which the transaction is agreed upon. We will begin by discussing his outcome-related mistake.

In his discussion of college athletics, he claims that only a handful of schools can be said to be gaining from their transactions with student-athletes because only a handful of schools actually enjoy a profit. Profit, however, is a technical economic term: profit is equal to revenue (amount of money made) minus expenses (amount of money spent). If a company makes 10 billion dollars but spends 10 billion dollars, it has not turned a profit. While it might make sense to judge publicly traded companies using this standard, it makes little sense to use it as a basis from which to judge whether or not a school is gaining from its transactions with student-athletes.

If an athletic department makes tens or hundreds of millions of dollars but hires new employees, pays employees more, and builds new facilities, it will not turn a profit, but will still have gained. Take, for instance, the University of Alabama. In 2008, Alabama had the highest revenue of any athletics department in the NCAA, making 123 million dollars. ${ }^{148}$ Total expenses were just almost equal to that,

${ }^{148}$ ESPN. "College Athletics Revenue and Expenses - 2008. http://espn.go.com/ncaa/revenue 
meaning that the University of Alabama athletics department turned a profit of barely $\$ 400,000$. It does not make sense to say that the University of Alabama barely gained from its transactions with student-athletes: these transactions resulted in an enormous amount of money being generated, just not a huge profit. Further, it seems reasonable to argue that schools benefit from the transaction in ways that might not be measured financially. Having a winning program that draws national media attention could have all sorts of benefits to the university: it could attract more students, it could attract better researchers, and it could help bring in more money from alumni donations which can further improve campus recruiting by improving facilities. This is why Wertheimer's use of athletics department profit as the judge of whether or not a school has gained from its transactions with studentathletes is misleading.

However, Wertheimer is still right that not all schools can be said to gain disproportionately to the student-athlete, and thereby that not all student-athletes are exploited. Whether or not a given student-athlete is exploited has to do with what the athlete receives in comparison to how much he would receive in a "fair" world. ${ }^{149}$ While the breakdown is likely impossible to do perfectly, it seems reasonable - reasons forthcoming - to split the student-athletes into two categories: those who play men's basketball and football in the top five conferences (PAC-12, SEC, Big Ten, Big 12, ACC), and those who do not. These two sports in these five conferences (known as the power conferences) are responsible for the vast majority

149 Wertheimer, Exploitation, 90. Wertheimer says that what a student-athlete might receive in a "fair" world can be thought of as what a student-athlete would receive if there were an open market for student-athletes. 
of revenue created in college sports, and so it is reasonable to say that each of the schools in these conferences gains from its transactions with the players on those teams.

Breaking players into two broad groups, however, is not an entirely accurate way to determine who is being exploited and who is not. Rather than making vast generalizations about groups of players and groups of schools, the best approach is to judge each transaction individually. Wertheimer is clear that a potentially exploitative transaction is between a single player and a single school. Players have different talents, and likely deserve larger or smaller portions of revenue based on how their talent contributes to the revenue created. So while we can broadly state that men's basketball and football players in major conferences are likely exploited and most other student athletes are not, there are obvious exceptions to this guideline.

For instance, the worst player on a power conference men's football team (a team comprised of around 70 players) to receive a scholarship might be getting a fair deal. His individual contribution to the revenue created by his team and the number of games that his team wins might in fact be less than the value of his scholarship. In the opposite case, some players on men's basketball teams outside of a power conference might be getting less than a fair deal. If the best player on such a team leads his team to the year-end tournament (during which a huge amount of revenue is created, and where schools are handsomely rewarded for being a part of the tournament), his worth might be considerably higher than the scholarship he is receiving. 
So, my claim is not that only and all power conference men's basketball and football players are being exploited. Rather, my claim is that many of these players are exploited, and that there are also players outside of this group that are being exploited. However, correcting Wertheimer's outcome-related mistake does not challenge his argument that these student-athletes are not harmfully exploited. All I have done so far is argue that more student-athletes are exploited than Wertheimer claimed. To prove that this exploitation is harmful rather than mutually advantageous, we need to look more closely at the process.

\section{II}

Wertheimer's process-related mistake is far more serious. It involves two parts: the first is the failure to investigate the moral foundation of the Principle of Amateurism, and second is his failing to have recognized the role that each institution plays in creating the current monopoly enjoyed by the NCAA. Let us begin with The Principle of Amateurism, which we have talked about at length. It is a non-commodification claim made by the NCAA that essentially claims that the involvement of money in sport ruins the physical, mental, and social benefits to be derived.

The principle is the cornerstone of the current college athletics system, and, as has already been discussed, there are two stated goals of the Principle of Amateurism: to ensure that student-athletes do not receive financial benefits other than what they receive from their athletic scholarship, and to "recognize the 
primacy of the academic mission of its institutions." ${ }^{150}$ The goal of keeping money out of student-athletes' hands is to make sure that athletes remain involved in athletics for the goods intrinsic to athletic competition. ${ }^{151}$

As discussed in Chapter Two, there are theorists who argue that money actually does spoil the social goods (teamwork, competition, fraternity/sorority, to name a few) associated with sport. And to ensure that students at a university remain focused on academics is a valuable goal. In Chapter Two I argued that this position - that money spoils the good associated with sports - is a bad one, and that the single issue that can arise with money being involved in sport can be easily fixed by putting in safeguards such as salary caps. But, let us imagine that you found my argument unconvincing, and that this position (that money spoils the goods associated with sport) is actually correct. If this is indeed why the NCAA wants to stop athletes from being paid, it seems reasonable to say that the same principle would apply to all those involved in the sport.

Remember some of the numbers I discussed in Chapter One: American college athletics is an 11 billion dollar a year business. The University of Texas, which has the largest athletics-related revenue of any college in the US, received 163 million dollars of revenue in 2013 from its athletics programs..$^{152}$ The average salary for a head coach whose team made the 68-team final tournament in men's basketball in 2014 was just under two million dollars a year, with the highest paid

150 NCAA Manual 2013-2014, Section 12.01.4

${ }^{151}$ NCAA Manual 2013-2014, Section 2.9

152 Steve Berkowitz et al, "NCAA Finances," USA Today. http://www.usatoday.com/sports/college/schools/finances/ 
coach bringing in just fewer than ten million dollars. ${ }^{153}$ In Division 1 college football in 2012, the average coaching salary was 1.64 million dollars and the highest paid coach makes just fewer than six million dollars. ${ }^{154}$ The average athletic director of a Division 1 school made around $\$ 500,000$ in 2013 , with the highest paid athletic director making 3.2 million dollars. ${ }^{155}$ This does not even begin to describe the huge number of people whose salaries are paid by revenue created by athletics programs. The University of Texas, to stay with the example, has 471 people listed on their staff directories page. ${ }^{156}$ This all happens within an organization that claims money spoils sports.

Further evidence to the fact that the NCAA is not genuinely concerned with its non-commodification claim is supplied by one of lawsuits discussed in Chapter One. The class-action lawsuit, which takes aim at the NCAA's Principle of Amateurism and the current cap on player compensation, argues that the NCAA has steered far from its Principle of Amateurism and onto a path of commercialization. It argues that the NCAA has done as much as possible to commercialize the sport and

153 Josh Peter and Steve Berkowitz. "Special Report: Coaches hit jackpot in NCAA system." USA Today, April 2nd, 2014. 2014. http://www.usatoday.com/story/sports/ncaab/2014/04/02/ncaa-tournamentbasketball-coaches-compensation-obannon-case/7208877/

154 Erik Brady, Jodi Upton, and Steve Berkowitz. "College football coaches continue to see salary explosion." USA Today, November $20^{\text {th }}, 2012$.

http://www.usatoday.com/story/sports/ncaaf/2012/11/19/college-footballcoaches-contracts-analysis-pay-increase/1715435/

155 Erik Brady, Jodi Upton, and Steve Berkowitz. "Major college Ads averaging over $\$ 500,000$ in pay." USA Today, March 6, 2013.

http://www.usatoday.com/story/sports/college/2013/03/06/college-athleticsdirectors-salaries-increase/1964239/

156 University of Texas. "Staff Directory."

http://texassports.com/sports/2013/7/29/GEN_0729135557.aspx 
to bring in more revenue. ${ }^{157}$ Teams often switch conferences in order to make more money from media deals, and end up playing games far from their own campus as a result. The motivation behind all of these actions is financial gain. As the lawsuit points out, schools completely ignore what is good for the student-athletes, and do whatever it takes to bring in more revenue. It seems quite clear that despite demanding a commitment to non-commodification from its players, the NCAA itself has in fact abandoned an amateur model of sport, and has increasingly commercialized college athletics.

The second goal of the Principle of Amateurism is to ensure that studentathletes remain students first. But, if we remember a recent ruling by the National Labour Relations Board (NLRB) seems to discredit the notion that student-athletes are students first. In December of 2013, the Northwestern University football team brought a case to the NLRB with the purpose of gaining the right to unionize and bargain for their services. After hearing testimony from both sides, the NLRB ruled that student-athletes at Northwestern were employees that had the right to unionize. The NLRB found that student-athletes on the football team spent far more time on their sport than they did on their schooling, and that there were times that they were unable to attend classes due to scheduling conflicts with football.

Despite what the NCAA claims, student-athletes at the Division 1 level are primarily athletes. This is not to say that they are not also students, but it is to say that they are certainly not primarily students. In a more recent matter that has turned into a separate class action lawsuit (also discussed in Chapter One), the

157 Jenkins et al vs. NCAA (2014), 4:2014cv02758, United States District Court, District of New Jersey. http://a.espncdn.com/pdf/2014/0317/NCAA_lawsuit.pdf 
University of North Carolina was found to be giving credits to certain studentathletes for coursework that the students did not actually do. ${ }^{158}$ This is just another example of academics taking a secondary role behind athletics in Division 1 college sports in the United States.

Here, we begin to see how the NCAA harmfully exploits its players. Money is already involved in college sport and the (false) non-commodification claim at the foundation of the Principle of Amateurism cannot legitimately justify the denial of that money to players alone. Regardless of the strength of the claim itself, the noncommodification claim upon which the Principle of Amateurism depends cannot be selectively applied. Either money in sport is wrong full stop, and so we must get rid of it altogether, ${ }^{159}$ or we must allow college athletes to get their fair due. The fact that the NCAA illegitimately applies the claim to their student-athletes is indefensible. Also, I hope to have shown that the Principle of Amateurism cannot be defended on the basis of its second stated goal, because student-athletes have been found to be students second, not first.

That Wertheimer does not recognize this is the first part of why he makes what I have called his process-related mistake about exploitation and the NCAA. What the NCAA has done by withholding payment from players is nothing short of fraud. On the basis of a clearly false claim, the NCAA is getting student-athletes to agree to not being paid. A major part of the transaction between schools and their student-athletes is based upon a lie told by the NCAA and its member schools.

158 Ironically, the faculty member found to be most at fault was a philosophy professor who happened to be the head of the Centre for Ethics at the university. 159 I argued against this claim in Chapter Two. 
Because the NCAA misrepresents the facts of the case, the student-athletes' consent is not fully informed. This misrepresentation of the facts by NCAA schools is exactly the type of scenario that Wertheimer would describe as fraud. Wertheimer is clear that any exploitative transaction that is fraudulent in nature is a case of harmful exploitation.

\section{III}

The second part of Wertheimer's process-related mistake is that he fails to recognize the role that institutions play in creating a monopoly that allows them to benefit from the fraudulent amateurism claim. The same class-action lawsuit mentioned above takes aim at the NCAA's monopoly. It seeks to end what it claims is unlawful price-fixing by the NCAA and its five major conferences. ${ }^{160}$ As discussed in Chapter One, price-fixing is illegal in the United States unless it has pro-competitive benefits. The lawsuit claims the NCAA and its member institutions have purposely created a monopoly with the specific goal of illegitimately putting a ceiling on player payment. ${ }^{161}$

As I discussed in Chapter Three, monopolies are actually mentioned both in systemic and transactional accounts of exploitation. I argued briefly that this is

\footnotetext{
160 Jenkins et al vs. NCAA.

${ }^{161}$ In 1984, the NCAA was found to be in violation of the Sherman Act by attempting to limit the number of live football games that could be televised locally. In 1998, the NCAA was again found to be in violation of the Sherman Act by attempting to set a price cap on what part time coaches could be paid. Most recently - in 2001 - the NCAA was sued by five of its member institutions under United States anti-trust law. While the case did not go to court, the legal action resulted in the NCAA settling, and paying a significant amount to the suing schools. From: Jenkins et al vs NCAA.
} 
because there are two things that are really at the core of most accounts of exploitation: one, that is has something to do with unfair outcomes; and two, that this unfair outcome often has something to do with unequal bargaining power. Monopolies are the prime example of this type of claim. Monopolies create a position of bargaining strength for those involved, and a position of bargaining weakness for those with whom they are bargaining. Because of this inequality in bargaining strength, the outcome of transactions between an individual and a monopoly is unfair.

One might ask how an individual institution should be held responsible for the actions of a large group, but the group cannot function as a monopoly without the cooperation of each individual institution. Any high school athlete that wishes to play at the next level in basketball or football (particularly if they also wish to pursue a post-secondary education) has little choice but to play in the NCAA. Individual schools, or collections of schools, could choose to create their own league with their own set of rules. By deciding to join the NCAA and abide by its rules, each school is choosing to create and contribute to a monopoly. The NCAA example is a perfect example of monopoly in practice. They use their advantage as a monopoly, along with a fraudulent non-commodification claim (the Principle of Amateurism), to deny pay to student-athletes. This argument - that NCAA purposely engages in monopolistic practice - is supported by former NCAA president Walter Byers. In a 
published article from 2010, he says the following: "Amateurism is not a moral issue; it is an economic camouflage for monopoly practice."162

Having a monopoly is what allows schools to take advantage of the Principle of Amateurism in order to exploit student-athletes. Imagine that only half of the major schools abided by NCAA rules and made the false amateurism claim; the other half paid their players a fair share of the revenues. The schools that abided by NCAA rules would have little chance of attracting the best players, and likely the revenue created from their teams would decline drastically. But because the NCAA has a monopoly on college athletics, players have no choice but to go to a school that abides by NCAA rules. It is the combination of the Principle of Amateurism and the monopoly on college sports that allows schools to force revenue-generating student-athletes to accept less compensation for their services than they deserve.

This monopoly looks coercive because the NCAA is purposely limiting options that potential student-athletes have in order to gain an advantage. But this does not qualify as coercion on Wertheimer's definition thereof. He argues that coercion occurs only when $A$ threatens to make $B$ worse off if $B$ refuses to transact on A's terms. NCAA schools are doing many morally dubious things, but this is not one of them. Wertheimer's definition of coercion is far too narrow. Coercion, in the ordinary sense of the term, has to do with manipulating a situation with the goal of limiting the potential choices of another in order to gain an advantage over them. Surely I can coerce someone without threatening to make them worse off. I coerce

\footnotetext{
162 National College Players' Association, Introduction and Background. http://www.ncpanow.org/research/body/Introduction_and_Background.pdf
} 
you when I say "your money or your life," but I also coerce you when I reconstitute your available options such that I benefit more from your choices than you do,

Granted, this account of coercion is one that requires more argumentation. But it is also one I need not fully establish here. Wertheimer is very clear that, even if it is not coercive, if $A$ plays a direct causal role in creating the circumstances that allow for $A$ to exploit $B$, then the moral force of the exploitation is still quite strong. See this example, from his SEP entry:

By contrast with cases of coercion and fraud, there are at least some cases of alleged exploitation in which $B$ 's consent is not defective in either of these ways. In many cases of alleged exploitation, $A$ gets $B$ to agree to a mutually advantageous transaction to which $B$ would not have agreed under better or perhaps more just background conditions, where $A$ has played no direct causal role in creating those circumstances, [and] where $A$ has no special obligation to repair those conditions. ${ }^{163}$

Here, we see that if one of these conditions is not met, the moral force increases drastically. So, the fact that NCAA schools play a direct causal role in creating the circumstances that allow for them to exploit student-athletes is extremely significant.

On my view, creating circumstances - particularly by committing fraud - in order to take advantage of these circumstances is a form of coercion. It certainly fits with what I have described above. So NCAA schools are - on my view - acting coercively. While Wertheimer would disagree, he would still agree that creating unjust conditions in order to take advantage of them and exploit someone is a way of harming the process. On his view this is secondary to coercion; on mine it is a

163 Wertheimer, Alan. "Exploitation," The Stanford Encyclopedia of Philosophy 
form of coercion. In either case, the transactional process has been impaired, resulting in harmful exploitation on the part of NCAA schools.

Wertheimer argues that student-athletes in the NCAA are exploited by their schools in a mutually advantageous way, and insofar as it is mutually advantageous, nothing needs to be done to rectify it. I have argued that - if we correctly apply his own theory - student-athletes are actually harmfully exploited by their schools. There are certain student-athletes - mostly those who play men's basketball and football for teams that create significant revenue for their schools - who receive less than they would in an ideal world. While Wertheimer and I both agree about this, I have argued that the number of schools that exploit their student-athletes is larger than Wertheimer allowed. I have argued further that NCAA schools actually act fraudulently and coercively in their transactions with student-athletes. A necessary condition for a case of mutually advantageous exploitation is that $A$ acts neither coercively nor fraudulently. Wertheimer is clear about this: he says that any exploitative transaction involving fraud or coercion is a case of harmful exploitation.

I have tried to show that the exploitative transaction between certain NCAA schools and certain student-athletes involves both coercion and fraud, and is therefore a case of harmful exploitation. The principle of permissible exploitation therefore does not apply, and the harmfulness of these transactions should - on Wertheimer's own view - be rectified. We ought to interfere with the transaction and design a new system for college athletics. The outcome of this interference would be an abandonment of the Principle of Amateurism, which would mean student-athletes in the NCAA would be allowed to receive financial reward for their 
athletic involvement. We must introduce, to use the common term, pay-for-play in college athletics. 


\section{Chapter Five \\ Practical and Theoretical Issues with the Introduction of Pay-for-Play}

In the previous chapter I argued that Wertheimer made two mistakes in the application of his theory to the case of college athletics, and that when we correct these mistakes we see that there is a group of student-athletes in the NCAA that are harmfully exploited by their schools. I concluded that the moral force of this harmful exploitation is quite strong, that the principle of permissible exploitation therefore does not apply, and that these transactions ought to be interfered with. The remainder of this paper will be spent discussing exactly how these transactions ought to be interfered with. The answer is not to abandon athletics at the college level, but instead to put in place a system that allows for college athletics to avoid the exploitation of student-athletes. This new system would involve paying certain student-athletes, an idea that is commonly called pay-for-play.

In this chapter I will do three things. First, I will identify practical issues that might arise with the introduction of pay-for-play; second, I will present an initial proposal for a system that I think deals with those practical issues; and third, I will identify and respond to a serious theoretical issue with my proposed redesign of college athletics. The theoretical issue centers on the morally arbitrary factors that would lead to an inequality between men's basketball and football players and all other players. If we place any importance on equality, this is a serious issue. As I will show, however, we can institute a pay-for-play model without abandoning a commitment to equality, properly understood. 
There are a number of worries that might arise in a pay-for-play college athletics system. The first is deciding who exactly should get paid, and hereafter I will refer to this as the Precision Issue. As I described in the previous chapter, figuring out exactly which student-athletes are being exploited is difficult. There are obvious cases of exploitation, and obvious cases of non-exploitation, but there is a large middle ground in which it might be difficult to tell if a student-athlete is being exploited. Figuring out where to draw the line for payment is an important obstacle that must be overcome, and I will begin (but by no means claim to finish) doing that work in this chapter.

The second issue that might arise in a pay-for-play system is figuring out a way to make sure that student-athletes remain student-athletes and do not become athletes only. I will call this the Academic Issue. One of the stated goals of the Principle of Amateurism is to recognize the primacy of the academic mission of colleges. While I do not argue that all student-athletes should focus primarily on school (for instance, a projected $1^{\text {st }}$ round pick in the NBA might have good reason to focus primarily on basketball and secondarily on academics), academic success is still enormously important for the vast majority of student-athletes. Further, universities are meant to be educational institutions, and maintaining the academic integrity of an educational institution is vital. Because of that, it is important that the new system finds a way to ensure the academic success of student-athletes and respect the academic integrity of member institutions. 
Considering the trouble that certain NCAA programs have had ensuring that their student-athletes excel academically, this is a possible area for huge improvement. Quite simply, the NCAA has failed in its attempts to ensure the academic success of its student-athletes. So, while I do agree that it is important to ensure the academic success of student-athletes, I do not think that this worry about academics would be unique to a new system of college athletics. Given the academic issues of many Division 1 schools, the worry about athletics affecting academics is already legitimate. While designing a pay-for-play system in college athletics, we should also aim to make sure that student-athletes can be successful academically.

A third worry that we must keep in mind in designing a new system for college athletics is the effect that pay-for-play would have on parity in college athletics. I call this the Parity Issue. By parity, I mean having a league in which all (or most) competing teams have a legitimate chance to win. As I discussed in Chapter Two, the one legitimate worry about the involvement of money in sport is that teams might be able to essentially buy wins or championships. In Major League Baseball, for instance, no team outside of the top 12 in spending has won a World Series in the last 15 years. Each year, 20 teams play in the MLB that have no chance of winning the World Series. This shows that having an open market to pay for talent in competitive sport is problematic. As with the academic issue, I do not think the parity worry is unique to a pay-for-play system.

While technically each of the 351 schools in Division 1 basketball has a chance of winning the National Championship, only one team outside of a "power 
conference" has actually won since $1967 .{ }^{164}$ College athletics already has an issue with parity. Admittedly, introducing pay-for-play could worsen the issue unless measures were taken to mitigate it. As I mentioned in Chapter Two, there are tools (salary caps, for instance) to avoid this issue and limit the effect that money has on a team's ability to win. These tools would have to be put to use in order to make sure college athletics thrived in a pay-for-play era.

The last possible issue with pay-for-play is what I will call the History Issue, and it relates mostly to college basketball and March Madness, the year-end tournament in NCAA basketball. Fans of basketball have come to know March Madness as one of the best sporting events of the year, because any team in the 68team field has a chance at winning the national championship. With smaller, unheralded teams (often called "Cinderellas") with tiny budgets upsetting major teams with enormous budgets, it is quite simply very compelling to sports fans. When Cinderella teams are able to make deep runs in the tournament, it is only because they represent some of the things we value most in a team sport: teamwork, dedication, skill, and an ability to rise to the moment. A redesign of college athletics would put March Madness in jeopardy, and an argument must be made to show why this is necessary. With these four significant worries in mind, the next section will outline an initial proposal for a pay-for-play college athletics system that would avoid the exploitation of student-athletes.

164 The University of Nevada, Las Vegas (UNLV) won the National Championship in 1990. They play in the Mountain West Conference, which is considered one of the stronger non-power conferences. 


\section{II}

The first part of my proposal is that we split Division 1 sports into two sections: the Men's Basketball and Football Division (MBFD), and the Other Sports Division (OSD). MBFD would have its own set of rules, and would be self-governing. Recently, an economist has suggested a similar idea, with each school having two athletic directors, each in charge of one of the new divisions. ${ }^{165}$ Now, the OSD could operate under the same rules that the NCAA currently operates, just without the Principle of Amateurism. Student-athletes in the OSD still would likely be paid nothing more than the cost of an athletic scholarship: this is not in an attempt to protect amateurism, but simply an effect of the reality that the sports that these student-athletes play do not generate significant revenue. The student-athletes in the MBFD would have the opportunity to be paid, although not all of them will end up being paid.

Within the newly formed MBFD, there will be separate divisions. So what is currently NCAA Division 1 would be split into 2 groups: let's call them MBFD 1A, and MBFD 1B. MBFD 1A would consist of what we now call the power conferences, plus any other schools that demonstrate the ability to compete (both financially and athletically) with these schools. In Division 1A, we would institute pay-for-play. Which schools are in $1 \mathrm{~A}$ for basketball and football might differ, but likely there will be a lot of overlap. Certainly, though, some schools might be in $1 \mathrm{~A}$ for basketball and not for football, and vice versa. Division 1B would consist of all the other current

\footnotetext{
165 See Andy Schwarz, "College Sports Programs are Playing Poor, Here's How to Fix it." Vice, January $12^{\text {th }}, 2015$. https://sports.vice.com/article/college-sportsprogram-accounting-scam
} 
Division 1 schools, and would see no significant financial changes from the current system. Some sort of mechanism would have to be put in place to give schools the opportunity to move up into Division 1A, and to move schools down to Division 1B if need be. Players in 1B would still receive standard scholarship packages, though these packages would likely be more comprehensive than what players currently receive, and would be reviewed for fairness if revenue increased drastically for schools in this conference. We could imagine a bonus system being put into place, so that if programs in Division 1B saw an unusual increase in revenue, part of the increase could be given to players as a bonus.

Let us imagine that there would be somewhere between 65 (this is the number of schools in the power 5 conferences) and 100 schools in $1 \mathrm{~A}$ for men's basketball (we'll call it 80 for the purpose of simplicity). These 80 schools would be allowed to pay for 15 players on their men's basketball team. But, this would not be a true open market for talent: as I explained in Chapter Two, there are serious issues with allowing an open market in competitive sports. Like the NBA, there would be a salary cap that restricts the amount of money that schools can pay players. This is to make sure that schools remain on relatively even ground in their ability to recruit players, and so that the richer schools cannot simply buy all the best players. The salary cap would mimic the NBA's salary cap: it would be a percentage (in the NBA it is 50\%) of all the basketball-related income (BRI) that schools generated from the 
year before. Imagine that last year, the 80 schools brought in an average of 40 million dollars each. The salary cap for this year would then be 20 million dollars. ${ }^{166}$

With those 20 million dollars, schools can offer contracts to recruits however they see fit, with some guidelines. First of all, the contracts must each be guaranteed for as long as the student-athlete is advancing towards a degree. If a player leaves for professional sport in the time-period, it voids the remainder of the contract. Schools must also take out insurance policies for each player. If a player suffers a career-ending injury, he is paid out of this insurance policy and no longer counts towards the team's salary cap. There would also likely be a minimum contract offer, so that no player receives under a certain amount of money. This basic set of rules is a starting point: in all likelihood players would be represented by a union, and would be able to bargain for other things to be guaranteed.

Now, this initial set of rules around the salary cap would help with what I identified at the beginning of this chapter as the Parity Issue. In fact, with a welldesigned salary cap pay-for-play could be introduced and actually have a positive effect on parity in college sports. Right now, there are probably between five and ten schools in college basketball that have a massive recruiting advantage because of their national exposure and past success turning college athletes into professional athletes. These schools have been able to stock up on talent. If each school in $1 \mathrm{~A}$ had 20 million dollars to spend on player contracts, these big-time schools would have to choose which players they're willing to spend the most on. For instance, the

\footnotetext{
166 The salary cap system is far more complicated, and explaining it would involve knowledge of economics and finance that I simply do not have. The basic idea, though, is what I have explained it as.
} 
University of Kentucky (UK) currently has between five and 10 student-athletes on their basketball team that are projected to be first-round NBA picks. If UK could only offer one or two of these players the kind of money that other schools were offering them, they would almost certainly not get all of these players. Instead, they would be distributed more evenly throughout Division 1A. So pay-for-play - combined with a salary cap - could actually have a positive effect on parity in college sports.

So, the Parity Issue seems to be solved, or at the very least partially solved: certainly there are details in my proposal that would need to be worked out. But, my proposal creates the History Issue. To redesign college sports in this way would require a complete revamping of March Madness, and would take a way some of the thrill of Cinderella teams in the year-end tournament. Philosophically speaking, this objection might seem relatively uninteresting, unless we take the interests of fans to be more important than the exploitation of players. If we can stop a group of people from being exploited and the major downside is a different group of people enjoying a sport less, it seems clear that getting rid of the exploitation is more important. That being said, it will likely be a huge point of contention for college basketball fans. Besides the response that eliminating exploitation is - morally speaking - more important than fans' enjoyment of a game, there is also the possibility of allowing four teams from Division 1B to play in the Division 1A year-end tournament. The playoffs for the two leagues could be staggered, and then the top four teams from 1B could get bids to the beginning round of the $1 \mathrm{~A}$ tournament (which I am proposing would have 32 teams). This would allow for the excitement of Cinderella teams, and would allow teams from 1B to try to prove themselves against teams from 1A. 
So far, my proposals to have (at least initially) dealt with the Parity Issue and the History Issue: I have done nothing to address the Academic Issue. To solve this issue, I have three suggestions. The first is that academic standards be a requirement that is built into any contract that student-athletes sign with universities. For a contract to remain valid, student-athletes must progress academically each semester. How much they have to progress remains another issue, and this is where my second suggestion comes in. To ask student-athletes to carry the exact same course-load as non-athletes might be unfair: after all, by signing them to athletic contracts, schools are assuming that a significant amount of time will be put towards their sport.

My second suggestion is that student-athletes should not be required to progress academically at the rate of the average student. Instead, they should be required to advance - in a given year $-80 \%$ as much as a normal student would. This would meant that a student-athlete would require five years, rather than four, to finish the average undergraduate degree. The NCAA should therefore give five years of athletic eligibility rather than four. One need only look north of the border to see this system in place: the CIS (Canada's equivalent of the NCAA) gives studentathletes five years of eligibility. ${ }^{167}$ It seems common sense that giving studentathletes adequate time to focus on school and their sport should help increase academic performance. Recently, there has been talk in NCAA circles about mandatory freshman ineligibility. The idea being discussed is that in order to make

167 The CIS also requires that student-athletes maintain an academic average of 70\% in order to receive an athletic scholarship. This might be harsh, but it is certainly an idea that could be tinkered with. 
sure student-athletes adjust properly to college life and to the academic rigors of a college education, all freshman student-athletes would be ineligible to play in games. This seems like a drastic step. I believe there are many intermediate steps that can be taken before such a drastic measure needs to be put in place; however, if the intermediate steps end up failing then this is certainly a step that we could consider.

My third suggestion is that the NCAA institute an Academic Success Board that has three main goals. The first is to provide support and advice to athletic departments on how to design a program in which student-athletes can thrive as students. The second is to do an annual review of the academic performance of every single school in Division 1A. The third - in light of the academic scandal at UNC and other such events - is to randomly audit athletic departments throughout the year, checking on what types of courses student-athletes are taking and redflagging any dubious activity. These are three very large tasks, and the NCAA would have to fund enough staff to be able to do these jobs well. Funding could come from a yearly "tax" on Division 1A schools. Part of the stipulation for joining 1A could be that you pay an annual fee to support the Academic Success Board. If the NCAA takes all three of these steps - building academic progress rates into contracts, granting five years rather than four years of eligibility, and hiring an Academic Success Board, this should go a long way to ensuring that student-athletes can excel academically and that the academic integrity of universities is upheld.

The last major issue that remains is the Precision Issue. This is the one that seems hardest to fix. Given the fact that a schools' athletics-related revenue can rise 
or fall drastically in a given year, and that this determines whether an individual student-athlete is exploited, it becomes very difficult to figure out exactly which student-athletes deserve exactly how much money. There are, however, two possible ways to fix this. First, there should be a mechanism in place that allows schools in Division 1B to move up into Division 1A. If schools can show that they have the financial and athletic ability to compete at the $1 \mathrm{~A}$ level, they should be able to move up. Second, the salary cap system initiates a sort of delayed payment for financially successful (or unsuccessful) years. In any given year, the revenue created the year before determines the salary cap. This has two effects: first, if the revenue created in a given year is very high, the salary cap the following year will increase, meaning the players receive more money based upon this. Second, if the revenue created in a given year is very low, the salary cap the next year will decrease.

What this means is that in a year of financial growth, technically almost all of the players are exploited. In that year of financial growth, they are being paid based upon the previous year's revenue; they are not receiving what they should be receiving. But, this also means that players receive more than they should in a year of financial loss. Overall, it evens out to a fair deal.

This brings us to a serious argument against the salary cap. Because the salary cap prematurely caps the amount of money a player can make, there is a pretty good chance that, technically speaking, almost every player is being exploited in a system that involves a salary cap. The same is true in every league in the world that involves a salary cap. In the National Basketball Association, for instance, star players are starting to argue that they should be able to receive far more 
compensation. Absent a salary cap, teams would certainly pay a player like LeBron James more than he is being paid right now. Given that my entire project has aimed to show that college athletes are exploited, and that we should fix this, guaranteeing that they continue to be exploited seems like an odd thing to do.

There is a response to this seemingly strong line of argumentation against a salary cap: we have to choose between two moral wrongs in this scenario. A league with a salary cap guarantees that the involvement of money in sports does not allow teams to buy wins or championships, but it means players are exploited; a league without a salary cap guarantees that players are not exploited, but it allows money to intrude into sport in a negative way by allowing teams to essentially purchase wins and championships. We are forced to choose between two moral wrongs: either money negatively intrudes into the realm of sport, or players are exploited. Which is worse? This depends on the nature of the exploitation.

In Chapter Four I argued that student-athletes are harmfully exploited because they do not receive a fair portion of the revenue, and because the NCAA and its member institutions act coercively and fraudulently in the transaction with the student-athletes. If the NCAA and its schools adopted my suggestions, formally abandoned the Principle of Amateurism, and introduced pay-for-play, they would no longer be acting fraudulently. Further, student-athletes would likely be represented by some sort of union, which would mean that they would be playing under terms that were collectively bargained for. In this scenario, the NCAA and its schools cannot be said to be acting coercively either. This would mean that even though a salary cap would likely guarantee the continued exploitation of student-athletes, the 
moral force of that exploitation would be insignificant. Given the choice between money intruding on sport in a morally significant way or student-athletes being exploited in a morally insignificant way, the best choice would be to have a salary cap, thereby guaranteeing that student-athletes would be mutually advantageously exploited, but avoid the negative aspect of the intrusion of money into the realm of sport.

To conclude the section on practical issues, I have argued there are four worries that might come up with introduction of pay-for-play in college athletics. These are the Precision Issue, the Parity Issue, the Academic Issue, and the History Issue. I have argued if the NCAA completely restructures Division 1 sports and the rules that govern it, all four of these issues can be overcome. I have argued further that a restructuring could actually help the NCAA with some of the current issues it has when it comes to parity and academics. Introducing a salary cap that changes based upon revenue would deal with the Parity Issue by actually increasing parity in NCAA Division 1 sports, and it would deal (at least partially) with the Precision Issue; introducing an Academic Success Board with a threefold mission would deal with the Academic Issue; and playing around with allowing Division 1B teams to play in the Division 1A championship tournament in basketball would deal the History Issue. These are initial suggestions. There is serious work that needs to be done to figure out exactly how to design a new system for college athletics. I am not arguing for the immediate introduction of the proposal I just outlined; instead, I am arguing that there are practical ways to deal with any potential issues that would come up with the introduction of pay-for-play in college athletics. Further, I am 
arguing that any possible practical issues that might come up are far less morally significant than the current issue of student-athletes being harmfully exploited by their schools.

\section{III}

At this point, it is time to turn to the major theoretical critique of the system that I have proposed. I will first explain the critique, which I will call the Equality Issue, and then respond to it. The system I have just proposed for college athletics gives men's basketball and football players a chance to receive a substantial amount of the revenue that they create. The current system redistributes some of the revenue from men's basketball and football and gives it to other sports teams. Partially because athletics departments - and the NCAA - want to maintain nonprofit status, schools try to spend as much of their money as possible. This means that non-revenue sports (at most schools this means all sports other than men's basketball and football) end up with far bigger budgets than they would have otherwise, and that facility improvements happen for all sports at an impressive pace. ${ }^{168}$ Allowing men's basketball and football teams to pay their players might

168 The University of Texas athletics department, for instance, spends nearly 25 million dollars a year on the upkeep of their facilities. See Steve Wieberg, Jodi Upton, and Steve Berkowitz, "Texas athletics overwhelm rivals in revenue and spending." USA Today, May 14th 2012. http://usatoday30.usatoday.com/sports/college/story/2012-05-15/texasathletics-spending-revenue/54960210/1 And, even though $70 \%$ of their revenue comes from men's basketball and football, less than $24 \%$ of their expenses come from those same programs. This means that about two thirds of the revenue created my men's basketball and football goes to other programs or to general facility improvements. See: Cork Gaines, "Texas 
mean that budgets for other sports (and their facilities) would have to be reduced drastically. While the rationale behind this would be to make sure student-athletes are not harmfully exploited, it would have a negative effect on equality within athletics departments.

If we place any value on equality, this critique is serious. Let us imagine that the system I have outlined (or one similar to it) is actually put in place. What is it about men's basketball and football players that makes them deserve to be paid so much more than other student-athletes? Certainly we can say that they have worked very hard to get to the position that they are in, so there is an element of moral desert which might justify it. That being said, there are factors that are both hugely important and completely arbitrary that have led them there as well. There are, as I see it, two important (and connected) arbitrary features that are at play here.

The first of these factors is that they were born men in a world that values men's sports. Women's sports, as a matter of fact, do not generate the kind of interest (and therefore the kind of revenue) that men's sports do. The effect of this is that women, just by nature of being born women in a world that does not value women's sports, would be excluded from the opportunity to make the kind of money playing college sports that male athletes would have. This has nothing to do with how hard women work at their sport, and nothing to do with whether they display the sorts of qualities that we find valuable in an athlete. Put simply, there is

Longhorns: How The Richest School In College Sports Makes And Spends Its Millions." Business Insider, September 17th 2013. http://www.businessinsider.com/texas-longhorns-how-the-richest-school-incollege-sports-makes-and-spends-its-millions-2013-9?op=1\#ixzz3WSd1S8s8 
nothing morally significant that sets apart a male basketball player at a Division 1 school and female basketball player at the same school. But, if the system I proposed was in place, the male player would be receiving a huge financial benefit just because he is male athlete playing a sport that is valued commercially in our world. Interestingly, this example also brings up a practical issue. Under what is known as Title IX, which is a section of the United States Education Amendments of 1972, universities are required to give equal opportunities to men and women in athletics. There are a number of ways for schools to show that they are in compliance with Title IX, so it is not clear whether paying male student-athletes would necessarily mean a violation. If, for instance, schools showed they are giving an equal number of men and women the opportunity to play college sport, or that they are increasing men's and women's opportunities in athletics at similar rates, it might be fine that they were paying male athletes more than female athletes. ${ }^{169}$

The second arbitrary inequality that my proposal might be accused of ignoring and perhaps entrenching is between a male badminton player at a Division 1 school and the same male basketball player from the previous example. There is nothing morally significant about the fact that basketball is commercially valuable in a way that badminton is not, or about the fact that a men's basketball player likely has physical gifts that the badminton player does not. ${ }^{170}$ One might object that the

169 National Women's Law Centre. "Debunking Myths About Title IX and Athletics." http://www.nwlc.org/resource/debunking-myths-about-title-ix-and-athletics See also: Andy Schwarz. "How Not To Reform the NCAA." Vice, August 12th 2014. http://regressing.deadspin.com/how-not-to-reform-the-ncaa-1614553705

170 It actually might be the case that the things we find valuable in sport are present more in team sports than they are in individual sports. This is a line of argumentation that would take far more time to defend than I have here. 
badminton player made a choice to pursue a commercially unsuccessful sport. This would be ignoring the fact that high-level men's basketball and football players have genetic gifts (arbitrary factors) that help them enormously in their sport. While someone without these physical attributes can certainly still be good at basketball or football, it is an uneven playing field. Not just anybody can be a basketball player instead of a badminton player. Morally arbitrary physical factors and morally arbitrary factors about how the market values these factors are at play. The Equality Issue can be summed up in the following way: in the system I have proposed, multiple morally arbitrary factors end up having a significant effect on the equality of the distribution or benefits within an athletics program. If we think that there is nothing morally significant that separates student-athletes of different genders or sports, then equality demands an equal distribution of benefits or funding. Rather than giving a bigger share of those benefits to players who simply had the good luck of being born male and with a certain set of genetic gifts, we should distribute these benefits equally.

It is important, at this stage, to say exactly what I mean when I say equality. I do not mean identity, or that two players must receive the exact same monetary reward for involvement in sport. When I say there is an equality issue, I mean that there is a fairness issue. A good way to understand the difference is to appeal to John Rawls. Rawls argued that a just distribution of the benefits of a cooperative enterprise does not always need to be perfectly equal, but could still be fair. On his view, it would be rational to distribute some cooperative surplus in an unequal way, and this could even be seen to be fair to those who received the least. To show how 
this could be the case, Rawls devised a thought experiment that he called the original position. In the hypothetical original position, all members of society would be put behind a veil of ignorance: they would be stripped of any relevant knowledge that could create a bias. They would not know their gender, race, social status, or what skills the market would reward. While behind the veil, they would be asked to design a system that distributed the social goods within a society. Rawls argues that because people know that when the veil is lifted they could end up being the worst off in a society, and because they are rationally self-interested, people would design a system that guarantees an equal distribution of the social benefits, except where an unequal distribution is to the benefit of the worst off.

By stripping people of any morally arbitrary information about themselves, Rawls' original position guarantees a fair process; and a fair process guarantees a fair outcome. Note, though, that Rawls' conclusion is that some inequalities can be fair, but only those that are to the benefit of the worst off. One way to think about this is as an incentivization. If we allow surgeons, or engineers, or biomedical researchers to reap a larger portion of the wealth by allowing for higher pay, we incentivize smart people to do the type of work that benefits everyone - including the worst off - in society. It is undoubtedly to the benefit of the worst off to have good surgeons, good researchers, and good engineers. If we have to create an inequality in order for this to happen, this is a fair inequality.

Rawls is deeply committed to this view that people should not reap greater rewards in society or in any cooperative venture based on morally arbitrary features like gender or the possession of some set of genetic skills. What is 
interesting about his view, and why it is relevant of helping us address the Equality Issue, is that he says we do not need to distribute things strictly equally among everyone in order to avoid this worry. If some people are lucky and have skills and talents that generate huge amounts of social surplus, sometimes this can be to the advantage of the less lucky and less skilled as well. For Rawls, what fairness demands is equality, except in cases where inequalities actually work to the advantage of the least well off. Let us now look at how applying this view to athletics departments can actually help us resolve the equality issue otherwise generated by my pay for play model.

Imagine what the distribution of financial benefits within an athletic department would be if we used a Rawlsian-type original position. Imagine each athlete stripped of any knowledge about gender, size, or any information that might point to what sport they played. Behind this veil what would be the most reasonable way for the athletes to distribute the goods? Considering the fact that any athlete could turn out to be a woman playing the least commercially successful sport, one would think the athletes behind the veil of ignorance would design a system that shared the benefits of the commercially successful sports, rather than giving even more benefits to the players that played these sports. But this is not necessarily the case.

The extent to which the money would be shared might differ, but there are likely at least four key funding points that the athletes behind the veil would guarantee for each sport: first, enough money for scholarships for all of the players on all of the teams, both men's and women's; enough money for a coaching staff for 
all of the teams; enough money for the athletic and team gear required; and enough money to cover travel costs. In an ideal situation, the non-revenue generating sports would play in leagues that are more geographically defined in order to reduce travel time and travel costs. It is only the revenue-generating sports that might have to travel farther in order to play a schedule that accommodates TV schedules. ${ }^{171}$

However, after accommodating these guarantees for all sports teams it is likely that the players, thinking rationally, would actually allow for certain points of inequality within the system. Knowing that two sports generate the most amount of money, that these teams need to field good teams in order to continue bringing in that money, and that the more money there is the better it is for all the teams, the athletes would want to design a system that allowed for the commercially successful teams to have as big an advantage as possible while still protecting the four basic equality guarantees I listed above. This would mean enough money to attract the best players and coaches. So, giving the revenue-generating sports a far larger cut of the revenue would actually make sense because it is to the benefit of the teams that are the least commercially successful. An athlete behind the veil of ignorance would want to make sure that the revenue-generating sports continued to be as successful as possible, and giving them enough money to do this would be the rational thing to do.

In my initial proposal, I argued for something along a 50-50 split of revenue created between the players and the school. So, the basketball salary cap for players

${ }^{171} \mathrm{~A}$ lot of the money generated in college sports comes from TV deals, and TV providers will want to schedule attractive games. Historically, this has meant more extensive travel. 
would be based on $50 \%$ of the basketball-related income created by schools. Perhaps instead of 50-50, the schools should take more than $50 \%$ of the revenue created from men's basketball and football in order to make sure that the other sports continue to be funded in a way that reflects a commitment to equality, or that reflects a commitment to the fair process that would occur if all athletes went behind the veil of ignorance to determine funding. It might be the case the that $50 \%$ is enough to continue to spend fairly on all sports, but it might be the case that more is needed.

So, my response to the Equality Critique is to admit that an adjustment might have to be made, but also to argue that absolute equality of resources would not be the rational goal for athletes behind the veil of ignorance. Despite the fact that it is morally arbitrary that men's basketball and football are commercially valuable, it would make sense for athletes behind the veil of ignorance to allow men's basketball and football to receive far more of the revenue than other sports because it is to the advantage of the worst off. Pay-for-play could be introduced while still respecting a commitment to fair process and equality. While initially it appeared as though my system created unjustified inequalities between sports teams within athletic departments, it turns out that the inequality is justified and fair.

After identifying four practical issues and one theoretical issue with a redesigned college sports system, I have shown that my proposed pay-for-play system can actually deal with all of them. The Precision Issue, the Academic Issue, the Parity Issue, the History Issue, and the Equality Issue can all be dealt while 
introducing a pay-for-play system that avoids that harmful exploitation of studentathletes in the NCAA. 


\section{Conclusion}

The initial goal of this project was to lend clarity and credibility to the claim that student-athletes in the NCAA are exploited. I split this task into five chapters, with each chapter exploring an intermediate step to the final goal. The first chapter was an introduction to college athletics in the United States. In that chapter I introduced the NCAA and examined how and why the NCAA is set up the way it is. It was in this chapter that I first introduced the enormously important Principle of Amateurism, and the moral non-commodification claim that it is based upon. I then presented four legal cases that the NCAA is currently dealing with that lend credibility to the topic of exploitation in college athletics being not only worthy of philosophical inquiry, but actually in great need of philosophical inquiry.

The second chapter was an investigation of commodification literature in general, and of commodification of sport. In this chapter I closely examined the moral claim that is the basis for the Principle of Amateurism, namely that the goods associated with sport (teamwork, competition, skill) are in some way spoiled by the involvement of money in sport. I looked at commodification literature in general before focusing more closely on commodification and sport. In their book Ethics, Money, and Sport - The Sporting Mammon, co-authors Adrian Walsh and Richard Giulianotti advanced the claim that the commodification of sport can corrupt the goods brought about by being involved in sport as either a player or a fan. I

examined each of the four moral pathologies that Walsh and Giulianotti argue can come from the commodification of sport. In the end, I argue that only one of these possible moral pathologies is actually an issue, and that simple tools such as salary 
caps and amateur drafts can fix the issue. Further, I argued that the goods associated with sport are not the type of goods whose value cannot be realized while being bought or sold, and so the NCAA cannot apply this claim in order to deny pay to student-athletes. Overall, I claim that the commodification of sport is not a moral issue that we should be worried about, and so the NCAA's Principle of Amateurism relies on an outdated and false moral claim.

In Chapter Three I returned to the topic of exploitation. It is in this chapter that I examined what exactly it means to be exploited. For us to know whether or not student-athletes are exploited, I argued, we have to know what it means for somebody to be exploited. I began by examining system conceptions of exploitation. By drawing on work from contemporary Marxist theorists, and theorists who continue in the Marxist tradition, I eventually argued that this framework is not the right one to use in defining the particular moral harm of exploitation. After turning to the Kantian account of Allen Wood and to the transactional account of Robert Goodin, I eventually exposited Alan Wertheimer's theory of exploitation, and argued that his theory is the correct one to use. It fits with our considered judgments about what it means to be exploited, and it has the advantage of acknowledging that different cases of exploitation will have different moral forces.

In Chapter Four I took a closer look at Wertheimer's 1996 chapter on exploitation in college sports. After discussing his view on the topic, I argued that he makes two vital mistakes in applying his own theory to the case of college athletics in the United States. The first is that he misidentifies the scope of the exploitation, and that more student-athletes are exploited than he believes. The second is that he 
does not recognize that NCAA schools in fact act fraudulently and coercively in their transactions with student-athletes. Because of the importance of fraud and coercion in determining the moral force of exploitation in his theory, this second mistake is particularly important. It means that rather than being a relatively unimportant case of exploitation according to his theory, it is a case of exploitation with a strong moral force. Contrary to what Wertheimer concludes in his chapter on the topic, the principle of permission exploitation does not apply, and it is an exploitative transaction that ought to be interfered with.

The fifth and final chapter of this project was an initial proposal for how exactly college athletics in the United States should be redesigned in order to avoid the exploitation of student-athletes. I addressed four possible practical issues - The Precision Issue, the Academic Issue, the Parity Issue, and the History Issue - and one major theoretical issue - the Equality Issue - that could arise with the implementation of pay-for-play in college athletics. I argued that each of these issues could be overcome by designing a system with these possible issues in mind, and I argued that some of the current issues the NCAA is facing (academic issues and parity issues) could actually be significantly improved by introducing pay-for-play in college athletics. Because of this, I argued that we should implement pay-for-play in college athletics in order to avoid the harmful exploitation of student-athletes. At the beginning of this thesis, I presented five goals: first, I said that I would show that the topic of exploitation and college sports is one worthy of philosophical inquiry; second, I said that I would show that alleged issues with the commodification of sport are in fact non-existent; third, I said that I would show that 
Wertheimer's theory of exploitation best matches our considered intuitions about what exploitation means and that we should use this theory to examine the possible exploitation in college athletics; fourth, I said that I would show that studentathletes are in fact exploited, and this exploitation is morally significant to the point of the transaction warranting interference; and fifth, I said that I that would show that despite some possible practical and theoretical issues, a re-working of college athletics to implement pay-for-play and avoid the exploitation of student-athletes is not only feasible but could in fact help solve some current issues that the NCAA is having. These goals have now been met. 


\section{Bibliography}

Anderson, Elizabeth. "Ethical Limitations of the Market." Economics and Philosophy 6 (1990): 179-205.

Arneson, Richard. “What's Wrong with Exploitation?” Ethics 91 (1981): 202-27.

Brady, E., Upton, J., and Berkowitz, S. “Major college ADs averaging over $\$ 500,000$ in pay." USA Today, March 6, 2013. http://www.usatoday.com/story/sports/college/2013/03/06/collegeathletics-directors-salaries-increase/1964239/

Brady, E., Upton, J., and Berkowitz, S. "College football coaches continue to see salary explosion." USA Today, November 20 2012. http://www.usatoday.com/story/sports/ncaaf/2012/11/19/collegefootball-coaches-contracts-analysis-pay-increase/1715435/

Chavez, Linda. "How Colleges Exploit Athletes." New York Post, March 28 ${ }^{\text {th }}, 2014$. http://nypost.com/2014/03/28/how-colleges-exploit-athletes/

Daniels, Norman. "Equal Opportunity and Health Care." In Steinbeck et al. Ethical Issues in Modern Medicine: Contemporary Readings in Bioethics, 200-203. New York: Mcgraw-Hill, 2009.

Daniels, Norman. Just Health: Meeting Health Needs Fairly. New York: Cambridge University Press, 2008.

Gaines, Cork. "Texas Longhorns: How The Richest School In College Sports Makes And Spends Its Millions." Business Insider, September 17th 2013. http://www.businessinsider.com/texas-longhorns-how-the-richest-schoolin-college-sports-makes-and-spends-its-millions-20139?op=1\#ixzz3WSd1S8s8

Goodin, Robert. "Exploiting a Situation and Exploiting a Person." In Modern Theories of Exploitation, ed. A. Reeve, 166-200. London: Sage, 1987.

Goodin, Robert. Protecting the Vulnerable. Chicago: University of Chicago Press, 1985.

Goodin, Robert. Reasons for Welfare: The Political Theory of the Welfare State. Princeton: Princeton University Press, 1988.

ESPN. “College Athletics Revenue and Expenses - 2008." http://espn.go.com/ncaa/revenue 
ESPN. "MLB World Series Winners." http://espn.go.com/mlb/worldseries/history/winners

Jenkins et al vs. NCAA (2014), 4:2014cv02758, United States District Court, District of New Jersey. http://a.espncdn.com/pdf/2014/0317/NCAA_lawsuit.pdf

Johnson, Robert, "Kant's Moral Philosophy." The Stanford Encyclopedia of Philosophy (Summer 2014 Edition). http://plato.stanford.edu/entries/kantmoral/\#HumFor

Kant, Immanuel. Groundwork for the Metaphysics of Morals. http://www.earlymoderntexts.com/pdfs/kant1785.pdf

Lamar, Matthew. "Royals, Giants bucking recent payroll trends with World Series appearance." SB Nation Royals Review, October $20^{\text {th }}, 2014$. http://www.royalsreview.com/2014/10/20/7010007/royals-giantsbucking-recent-payroll-trends-with-world-series

McCants et el v. NCAA and the University of North Carolina at Chapel Hill (2015), 1:2015cv00176, Superior Court of North Carolina, County of Durham. http://www.cbssports.com/images/blogs/Hausfeld-complaint.pdf

Miller, Anthony W. "NCAA Division I Athletics: Amateurism and Exploitation." The Sport Journal, Jan 3. 2012. http://thesportjournal.org/article/ncaa-division-iathletics-amateurism-and-exploitation/

National College Players' Association. "Introduction and Background." http://www.ncpanow.org/research/body/Introduction_and_Background.pdf

National Women's Law Centre. "Debunking Myths About Title IX and Athletics." http://www.nwlc.org/resource/debunking-myths-about-title-ix-andathletics

NCAA. "Membership.” http://www.ncaa.org/about/who-we-are/membership

NCAA. “2013-2014 Manual.” http://grfx.cstv.com/photos/schools/usc/genrel/auto_pdf/201314/misc_non_event/ncaa-manual.pdf

Nielsen. "State of the Media: 2012 Nielsen Year in Sports Report." January 18 2013. http://www.nielsen.com/us/en/insights/reports/2013/state-of-themedia--2012-year-in-sports.html

NLRB Region 13 Case 13-RC-121359. "Decision and Direction of Election." March $26^{\text {th }}$, 2014. http://www.nlrb.gov/case/13-RC-121359 
O'Bannon v. NCAA (2009), 4:2009cv03329. United States District Court, District of Northern California. http://www.pbs.org/wgbh/pages/frontline/moneyand-march-madness/etc/licensing-litigation.html

Orinick, Steve. "MLB Team Payrolls." http://www.stevetheump.com/Payrolls.htm

Peter, J., and Berkowitz, S. "Special Report: Coaches hit jackpot in NCAA system." USA Today, April 2 $2^{\text {nd }}, 2014$. http://www.usatoday.com/story/sports/ncaab/2014/04/02/ncaatournament-basketball-coaches-compensation-obannon-case/7208877/

Pierce, D., Kaburakis, A., and Fielding, L. "The new amateurs: The National Collegiate Athletic Association's application of amateurism in a global sports arena." International Journal of Sport Management 11 (2010): 304-327.

Rawls, John. A Theory of Justice, Cambridge: Harvard University Press, 1971.

Rawls, John. Justice as Fairness: A Restatement. Cambridge: Harvard University Press, 2001.

Rawls, John. Political Liberalism. New York: Columbia University Press, 1993.

Rawls, John. "The Idea of Public Reason Revisited." The University of Chicago Law Review 64 (1997): 765-807.

Roemer, John. "Should Marxists be Interested in Exploitation?" Philosophy \& Public Affairs 14 (1985): 30-65.

Sandel, Michael. What Money Can't Buy: The Moral Limits of Markets. New York: Farrar, Straus, and Giroux Books, 2012.

Satz, Debra. Why Some Things Should Not be for Sale. New York: Oxford University Press, 2010.

Schwarz, Andy. "An Economist explains why Darren Rovell is wrong about paying college athletes." Vice, March 30 th, 2015. https://sports.vice.com/article/aneconomist-explains-why-darren-rovell-is-wrong-about-paying-collegeathletes

Schwarz, Andy. "College Sports Programs are Playing Poor, Here's How to Fix it." Vice, January 12 ${ }^{\text {th }}$, 2015. https://sports.vice.com/article/college-sportsprogram-accounting-scam

Schwarz, Andy. "How Not To Reform the NCAA." Vice, August 12 2 th 2014. http://regressing.deadspin.com/how-not-to-reform-the-ncaa-1614553705 
University of Texas. "Staff Directory."

http://texassports.com/sports/2013/7/29/GEN_0729135557.aspx

Berkowitz, Steve et al. "NCAA Finances." USA Today. http://www.usatoday.com/sports/college/schools/finances/

Walsh and Giulianotti, Ethics, Money and Sport: This sporting Mammon. New York: Routldege Publishing, 2007.

Walsh and Giulanotti, "This Sporting Mammon: A Normative Critique of the Commodification of Sport." Journal of the Philosophy of Sport 28 (2001): 5377.

Walzer, Michael. Spheres of Justice. New York: Basic Books, 1984.

Wieberg, S., Upton, J., and Berkowitz, S. "Texas athletics overwhelm rivals in revenue and spending." USA Today, May 14th 2012. http://usatoday30.usatoday.com/sports/college/story/2012-05-15/texasathletics-spending-revenue/54960210/1

Wertheimer, Alan. Exploitation. Princeton: Princeton University Press, 1996.

Wertheimer, Alan. "Exploitation in Clinical Research." In Exploitation and Developing Countries: The Ethics of Clinical Research, ed. Hawkins and Emanuel, 63-104. Princeton: Princeton University Press, 2008.

Wertheimer, Alan. "Exploitation." The Stanford Encyclopedia of Philosophy. http://plato.stanford.edu/archives/win2001/entries/exploitation/

Williams, Trey. "Bilas: NCAA shouldn't limit compensation." Johnson City Press, October 2 $2^{\text {nd }}$ 2013. http://www.johnsoncitypress.com/article/111460/bilasncaa-shouldnt-limit-compensation

Wood, Allen. "Exploitation." In Social Philosophy and Policy 12 (1995): 136-158.

Young, Iris Marion. Justice and the Politics of Difference. Princeton: Princeton University Press, 2011.

Zirin, Dave. "The NCAA: Posterboy for Corruption and Exploitation." The Nation, April 1 1st, 2013. http://www.thenation.com/article/173307/ncaa-posterboy-corruption-and-exploitation\# 